\title{
The faecal flora: a source of healthcare-associated infections and antibiotic resistance.
}

\section{Annika Samuelsson}

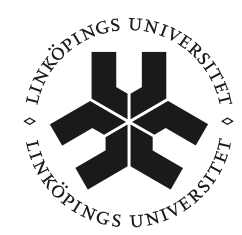

\section{Linköping University}

Division of Clinical Microbiology and Division of Infectious Diseases

Department of Clinical and Experimental Medicine

Faculty of Health Science

Linköping University, Sweden

Linköping 2013 


\section{The faecal flora: \\ a source of healthcare-associated infections and antibiotic resistance.}

(C)Annika Samuelsson, 2013

Cover/picture/Illustration/Design: Per Lagman LiU-tryck.

Published article has been reprinted with the permission of the copyright holder.

Printed in Sweden by LiU-Tryck, Linköping, Sweden, 2013

ISBN: 978-91-7519-591-9

ISSN: 0345-0082 
Synen är noll

på de långa

distanserna!

På nära håll

finns de många

nyanserna!

Tage Danielsson: Samlade tankar från roten. 1985-86 


\section{Table of contents}

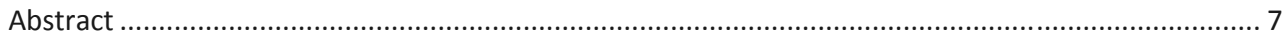

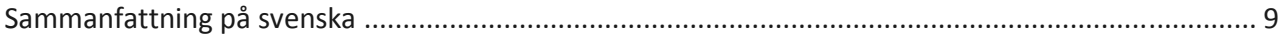

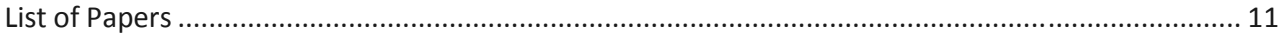

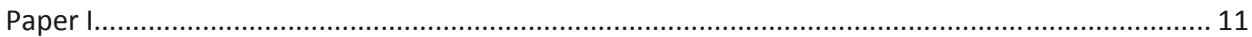

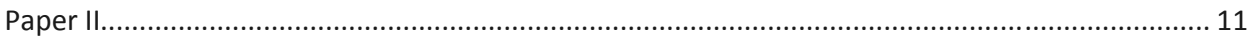

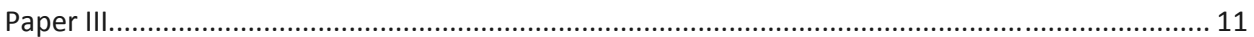

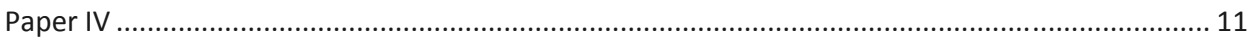

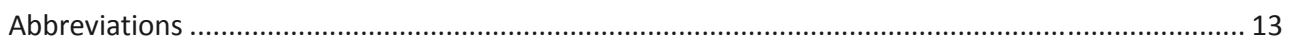

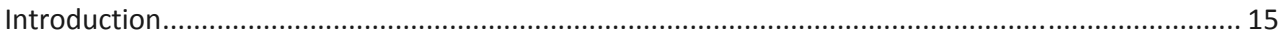

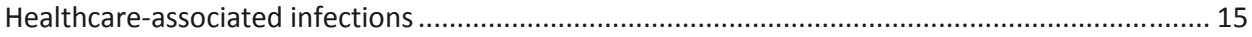

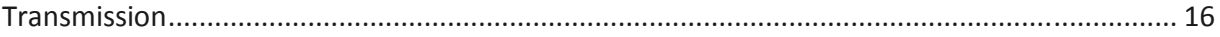

Preventing healthcare-associated infections .............................................................. 19

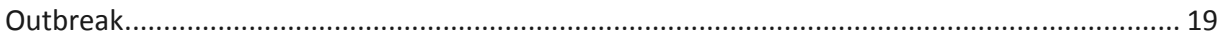

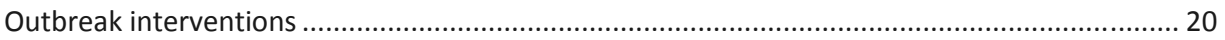

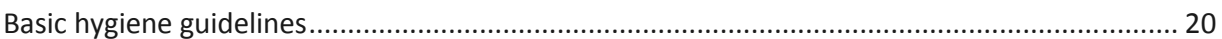

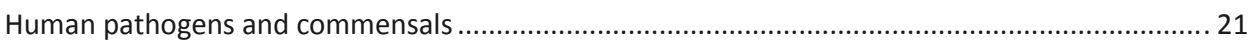

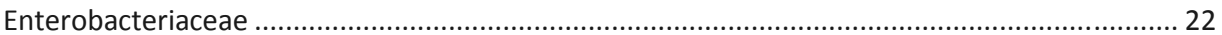

Pseudomonas, Stenotrophomonas and Acinetobacter .................................................... 22

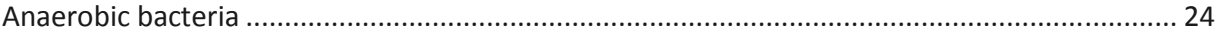

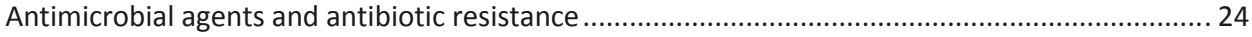

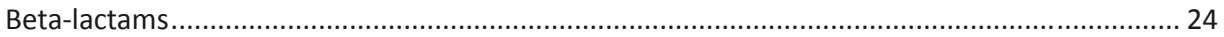

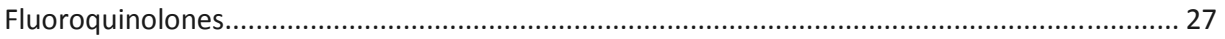

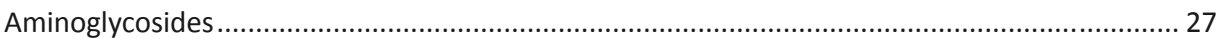

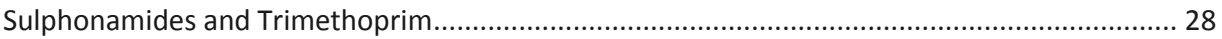

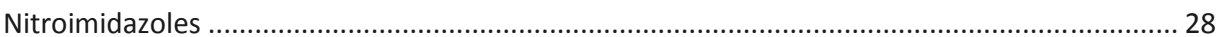

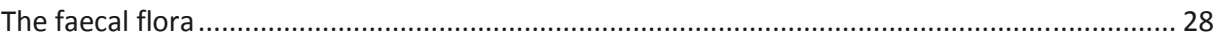

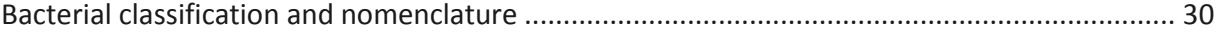

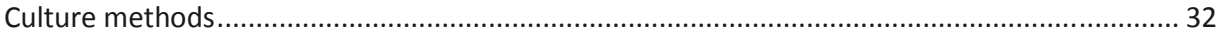

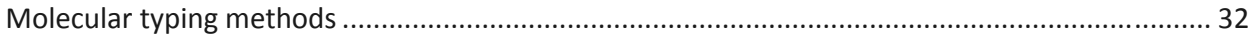

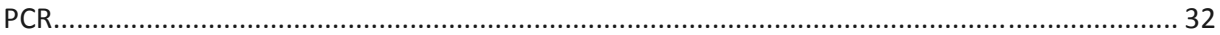

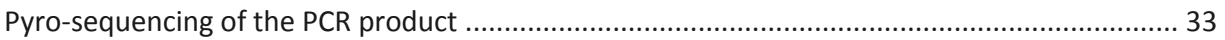

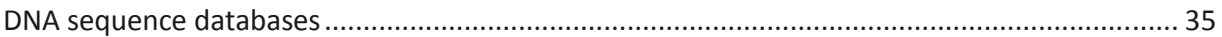

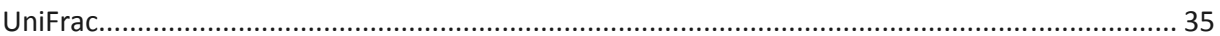




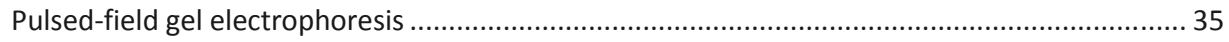

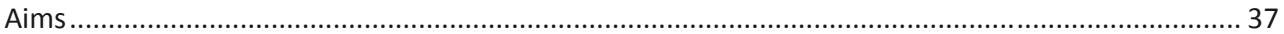

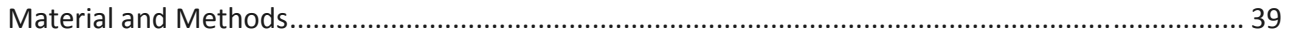

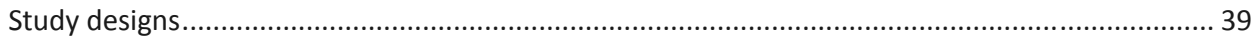

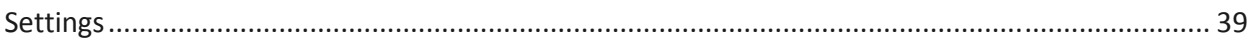

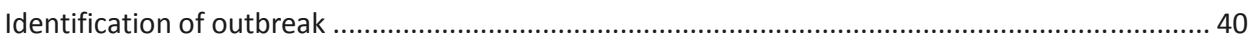

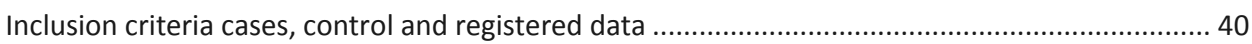

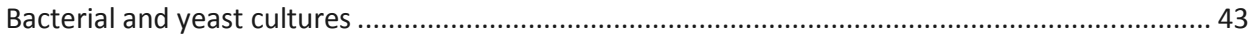

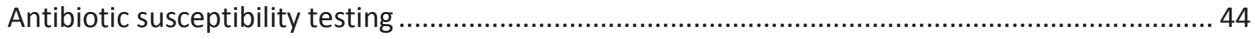

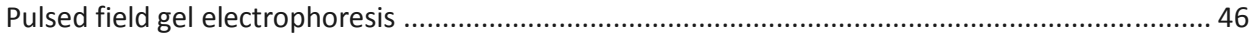

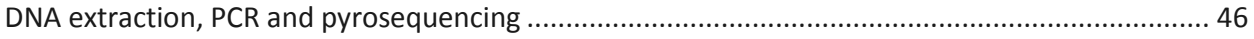

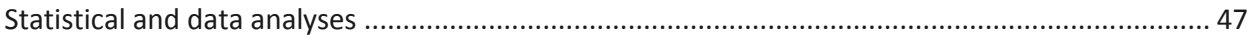

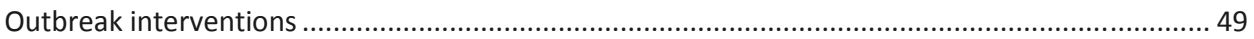

Monitoring compliance with basic hygiene guidelines .......................................................... 53

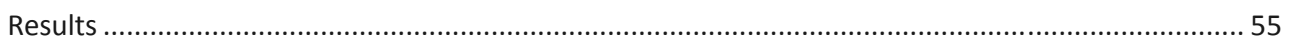

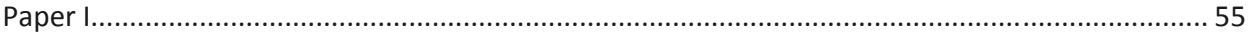

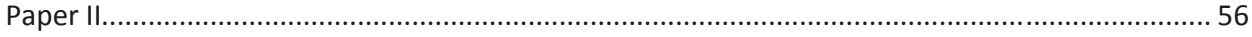

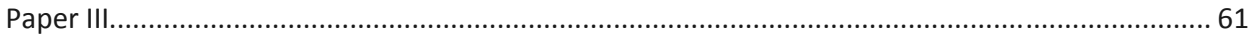

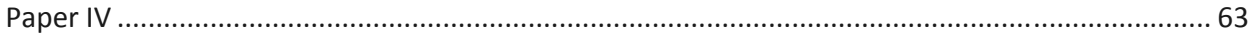

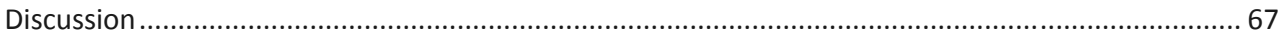

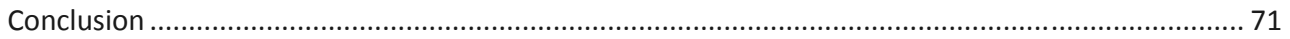

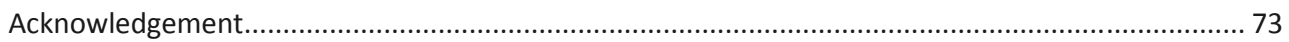

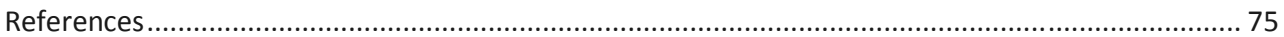




\section{Abstract}

Healthcare-associated infections (HAI) are important causes of mortality and morbidity, and antibiotic treatment is often necessary. Development and availability of new antibiotics are closely followed by development of resistance among microorganisms. During antibiotic therapy, a fraction of the antibiotic given is found in the gut. The human gut is an important reservoir of bacteria. Microorganisms residing or passing the gut is referred to as the gut flora or microbiota. The results of this thesis showed spread of Enterococcus spp between patients on a general intensive care unit, causing septicaemia. After improved hygiene, reorganisation of rooms and thorough cleaning of the unit, together with revision of antibiotic strategy, the incidence of septicaemia with Enterococcus spp fell. Investigation of patients treated for acute intraabdominal infections showed a shift in the aerobic faecal flora from antibiotic-susceptible Enterobacteriaceae spp towards Enterococcus faecium, yeasts and species of Enterobacteriaceae more resistant to antibiotics, after antibiotic treatment and hospital care. Investigation of recurrent outbreaks of Serratia marcescens sepsis in patients admitted to a neonatal intensive care unit showed different clones with each outbreak. Multiple hygiene interventions and revision of antibiotic strategy subsequently obviated recurrent outbreaks of sepsis, but spread of S. marcescens was not reduced until compliance with basic hygiene guidelines remained stable above $80 \%$. We also found that low gestational age at birth, ventilator treatment and central venous or umbilical catheters are independent risk factors for late onset sepsis. Investigation of the faecal microbiota in patients with acute appendicitis or diverticulitis revealed that disturbance of the faecal microbiota already existed on admission, with higher numbers of Enterobacteriaceae and less Bacteroides, Faecalibacterium, Ruminococcus and Prevotella prior to antibiotic treatment and hospitalisation, than the control population. After treatment and hospitalisation diversity increased significantly in the diverticulitis group, approaching the healthy controls in composition. 


\section{Sammanfattning på svenska}

Vårdrelaterade infektioner är en viktig orsak till sjuklighet och ibland dödlighet inom sjukvården, ca $10 \%$ av inneliggande patienter i Sverige, drabbas av en vårdrelaterad infektion. Ofta är antibiotika behandling nödvändig. Utveckling av nya antibiotika följs ofta av resistensutveckling bland mikroorgansismerna. Under antibiotika behandling passerar en del av antibiotikan tarmen där det finns och passerar ett stort antal bakterier - tarmfloran även kallad tarmens mikrobiota. I denna avhandling verifierades ett utbrott på en allmän intensivvårds avdelning av Enterokocker. Spridningen skedde mellan patienter, och gav i några fall upphov till blodförgiftning. Efter förbättringar av hygien rutiner, omorganisation av rum och en noggrann storstädning av enheten upphörde blodförgiftningarna med enterokocker. Vid undersökning av patienter som antibiotika behandlats och sjukhusvårdats för akut infektion i buken, visade det att den aeroba tarmfloran förlorade antibiotika känsliga Enterobacteriaceae arter och att Enterobacteriaceae arter resistenta mot fler antibiotika samt Enterococcus faecium och jästsvampar tillkom. Undersökning av återkommande utbrott av blodförgiftning med Serratia marcescens, på en neonatal intensivvårdsavdelning, visade att spridning förekom inom varje utbrott men att olika bakteriestammar låg bakom de olika utbrotten. Ett stort antal vårdhygieniska åtgärder och ändring av antibiotika strategier förhindrade, allteftersom återkommande blodförgiftnings fall med $S$ marcescens. Men spridingen av $S$ marcescens på avdelningen minskade inte förrän följsamheten till basala hygienrutiner stadigt låg över $80 \%$. Kort graviditetslängd, respirator behandling, central venkateter och katetrar i navlekärl är oberoende riskfaktorer för sen blodförgiftning. Vid undersökning av patienter med akut blindtarmsinflammation eller akut inflammerade tjocktarmsfickor framkom att tarmfloran (mikrobiotan) redan var rubbad med ökad förekomst av Enterobacteriaceae och minskad förekomst av Bacteroides, Faecalibacterium, Ruminococceae och Prevotella arter redan vid ankomst till akutmottagningen, jämfört med friska kontroller. I gruppen med inflammerade tjocktarmsfickor ökade diversiteten och närmade sig kontrollgruppen efter avslutad behandling. 


\section{List of Papers}

This thesis is based on the following papers that are referred to in the text by their Roman numerals.

\section{Paper I}

Samuelsson A, Isaksson B, Jonasson J, Monstein H-J, Berg S. Clustering of enterococcal infections in a general intensive care unit. Journal of Hospital infection. 2003;54:18895.

\section{Paper II}

Samuelsson A, Isaksson B, Jonasson J, Nilsson L.E, Eriksson O, Chabok A, Hanberger $\mathrm{H}$. Changes in the aerobic faecal flora of patients treated with antibiotics for acute intra-abdominal infection. Scandinavian journal of infectious diseases. 2012;44:820-7.

\section{Paper III}

Samuelsson A, Isaksson B, Jonasson J, Hanberger H, Olhager E. Late onset neonatal sepsis, risk factors and interventions: an analysis of recurrent outbreaks of Serratia marcescens 2006-2011. Submitted

\section{Paper IV}

Samuelsson A*, Wefer H*, Fahlén A, Agréus L, Nixon Andreasson A, Chabok A, Lundin $D$, Hanberger $H$, Engstrand L. Disturbed intestinal microbiota (dysbiosis) and micro dynamics in patients treated for appendicitis and diverticulitis. Manuscript

*These author contributed equally 


\section{Abbreviations}

\begin{tabular}{|c|c|}
\hline CPAP & Continous Positive Airway Pressure \\
\hline APACHE III & Acute Physiology And Chronic Health Evaluation \\
\hline CRP & C-reactive protein \\
\hline CT & Computor Tomography \\
\hline DDD & Defined Daily Doses \\
\hline EBC & Enterobacteriaceae \\
\hline ESBL & Extended-Spectrum Beta Lactamses \\
\hline GICU & General Intensive Care Unit \\
\hline $\mathrm{HAl}$ & Healthcare Associated Infections \\
\hline ICU & Intensive Care Unit \\
\hline LOS & Late Onset Sepsis \\
\hline LPK/WCC & Leukocyte Particle Concentration / White Cell Count \\
\hline NF & Non-Fermetative gramnegative bacilli \\
\hline NICU & Neonatal Intensive Care Unit \\
\hline PBP & Penicillin Binding Protein \\
\hline PPK & Platelet Particle Concentration \\
\hline PROM & Premature Rupture of the Membranes \\
\hline SMI & Swedish Institute for Communicable Disease Control \\
\hline spp & Species \\
\hline TISS & Therapeutic Intervention Score System \\
\hline UHL & University Hospital Linköping \\
\hline
\end{tabular}




\section{Introduction}

\section{Healthcare-associated infections}

A healthcare-associated infection is an infection occurring in a patient during the process of care in a hospital or other healthcare facility. The infection was not present or incubating at the time of admission or at the time of visit to a healthcare facility. They may appear in any setting, and may also appear after discharge(1). The source of HAl is either exogenous or endogenous. Endogenous infections may be prevented, for example, by preoperative skin disinfection of the patient, preoperative antibiotic prophylaxis, good clinical praxis and rigid hygiene routines at insertion of urinary catheters and central venous access devices (2). Prevention of endogenous infections is by preventing the patient from being infected by his/her own microbial flora. Exogenous infections are caused by infective agents from the surroundings, including medical devices and medical personnel, where the hands are the most important way of transmission (2). Healthcare-associated infections, including bloodstream infections, are an important cause of mortality and morbidity on the NICU(35). According to Borghesi et al. "Immunological immaturity, frequent use of invasive procedures and prolonged hospitalisation account for the high incidence of infections among pre-term infants" (6). Sepsis in new-born infants is often classified as either early onset sepsis (EOS), appearing up to $48 \mathrm{~h}$ after delivery and mainly due to bacteria acquired before or during delivery, or late onset sepsis (LOS) appearing 48-72 $\mathrm{h}$ postpartum and often caused by healthcare-acquired bacteria(7).

In 1847 Ignaz Semmelweis, at the time responsible for the First Division of Maternity Service at Allgemeine Krakenhaus in Vienna, observed the effect of hand-washing on mortality on the ward.

He observed that women delivered by physicians or medical students had a postpartum mortality rate, due to puerperal or childbed fever, of $13-18 \%$. Women delivered by midwifes, however, had a corresponding rate of $2 \%$. The intervention of hand-washing with disinfectant of the hands of physicians and medical students reduced the postpartum mortality to $2 \%(8)$. It was subsequently discovered that the physicians and medical students often came directly from a postmortem having not cleaned their hands in any way. This connection between a hygiene precaution and infection was 
established before the theory of "germs" causing infectious diseases by Pasteur in 1870(9), and the experimental proof of ability of bacteria to cause infection by Robert Koch in 1890(10). After the discovery of bacteria and their infective properties, models of transmission could be established.

\section{Transmission}

Modes of transmission of microorganisms from person to person are divided into contact transmission, droplet transmission and airborne transmission. Transmission from sources other than infected individuals is associated with common environmental sources or vehicles such as contaminated food or water. The most common way of bacterial transmission in the healthcare setting is contact transmission divided into direct and indirect contact transmission(11). The body surfaces of the healthcare provider that comes into contact with the patient in the care situation are usually the hands and forearms(12). Hand- mediated cross-transmission is a major factor in the current infection threat to patients in hospital (2). Transmission of microorganisms from hands, in the healthcare setting is dependent on five sequential steps:

1. organisms are present on health-care receiver's skin or on objects or surfaces in the near surroundings;

2. organisms must be transferred to health-care provider's hands;

3. organisms must be able to survive a sufficient length of time on the healthcare provider's hands or in the environment, to be able to come into contact with a recipient;

4. inappropriate or lack of cleansing of healthcare provider's hands between contamination and contact with the next patient or devices;

5. the contaminated hands must come in contact with a healthcare receiver, or surfaces or objects in the near surroundings (13). 
1. Infected wounds and eczemas are populated by pathogenic bacteria but even intact human skin is frequently colonised with pathogens such as Staphylococcus aureus, Proteus mirabilis, Klebsiella spp and Acinetobacter spp. The most heavily colonised body sites are the inguinal and perineal regions, but the axillae, trunk and upper extremities are also often colonised by pathogens.(13) . Humans shed about 10000 epithelial particles every minute and around 10\% of these particles hold viable microorganisms (14) that consequently contaminate the immediate surroundings. The intestinal tract and its vast content of microorganisms is also an important source of contamination of the environment, where faecal incontinence and diarrhoea facilitate dissemination of pathogens into the healthcare environment .(15).

Hand-touch sites are often contaminated by hospital pathogens such as MRSA, VRE, Acinetobacter and Clostridium difficile spores (16-19). An increasing number of studies show that cleaning or disinfection of the hospital environment can reduce transmission of healthcare-associated pathogens (20).

2. Healthcare providers contaminate their hands while performing "clean activities" such as taking pulse or blood pressure or lifting patients.(21) Touching the groin of a patient two times for 15 seconds, followed by hand-washing with soap and 5 minutes thereafter manipulating a sterile foley catheter led to Enterobacteriaceae being transmitted in 11 of 12 tests (22). Waters et al. investigated the carriage of .K pneumoniae, E. coli, P. aeruginosa, S. marcescens and E. cloacae on the hands of the nursing staff at a NICU, and infants infected by these agents over a two-year period. In $9 \%$ of bloodstream infections, conjunctivitis, skin and soft tissue infections, respiratory tract infections or infections in the central nervous system caused by these agents, PFGE identical clones were found on the nurses' hands. In this study K. pneumoniae and S. marcescens were more likely to be shared between nurses and infants (23). Bacterial contamination of hands increases with time in contact with the patient $(24,25)$. 
3. In an experimental model with healthy volunteers Noskin et al. showed that viable enterococcal strains survive up to 60 minutes on gloved or un-gloved fingertips (26). Enterococci were also found on inoculated environmental surfaces up to 1 week, and there was no reduction in colony count during the first $24 \mathrm{~h}$. Fryklund et al. showed that $50 \%$ of clinical $E$. coli and $K$. pneumoniae isolates survived on fingertips 6 respectively 2 minutes(27). Zachary et al. investigated healthcare workers' gowns (umbilical region and cuffs) for VRE after structured physical examination of 49 VRE carriers. Thirty-seven per cent of healthcare workers had VRE on their gowns after the examination (28). This emphasises the importance of bare forearms accessible for disinfection, and the importance of aprons to protect the gown.

4. With inappropriate hand disinfection, hands remain contaminated by potential pathogens and the risk for transmission remains after disinfection. The wearing of rings and artificial fingernails impair the effect of hand disinfection with even more pathogens remaining (29-33). The mode of handwashing and disinfection and the choice of soap and disinfectant also play a part in the reduction of pathogens on healthcare provider's hands (34-36). Nurses uniforms are shown to be contaminated while on duty with S. aureus, Clostridium difficile and VRE (37) to a large extent. Doctors' long-sleeved coats have been shown to often carry S. aureus on cuffs and in pockets after clinical work (38). Staphylococci have been isolated from a large fraction of neck ties worn by physicians on a British ICU (39). In an experimental setting viable S. aureus was found on polyester/cotton coats $24 \mathrm{~h}$ after contamination. Contamination with S. marcescens and $P$. aeruginosa showed viable bacteria when measured at 8 and $2 \mathrm{~h}$ respectively (40). Survival of and transmission of pathogens outside the natural environment is essential for spread of healthcareacquired infections. Long- sleeved uniforms easily get wet during hand disinfection and this provides a moistened environment perfect for the survival of bacteria, but also an interface with correctly disinfected hands. 
5. de Vries et al. described long-term carriage of S. marcescens on the hands of a healthcare worker with secondary cases of infection or colonisation with the same clone, among patients on a neurosurgical unit. The healthcare worker went on a 3 month leave and $S$. marcescens colonisation disappeared, but on the workers return S. marcescens colonisation among patients (41) re-occurred.

Factors that influence transfer of microorganisms from surface to surface are: the type of microorganism; the type of source and destination surfaces; and the moisture level and size of inoculum. Factors that influence the ability of a patient to become colonised by a microorganism are: the presence of medical devices; the disruption of normal mechanical and other host defence mechanisms; patient morbidity; and exposure to medications such as broad spectrum antibiotics(13). Even so, new colonisation with a potential pathogen isn't always followed by a clinical infection. The spread of pathogens such as MRSA in patients appears as colonisation (42) or as life-threatening infections (43). It is impossible to predict outcome of transmission of pathogenic bacteria in the individual case which is why transmission in general must be prevented. Studies have shown that 13$35 \%$ of outbreaks of HAl are due to cross-transmission in the healthcare setting (44).

\section{Preventing healthcare-associated infections}

The main goal of infection control is to reduce HAI. Standard infection control measures include the meticulous practice of hospital environment hygiene, hand hygiene, use of personal equipment and safe use and disposal of sharps (2). An inventory of healthcare-related harm and death in Sweden 2008 pointed out risk areas for harm and death related to healthcare, where HAI was of great importance. The following areas of improvement were identified: prevention of urinary tract infections; prevention of central line infections; and prevention of surgical site infections(45).

\section{Outbreak}

An outbreak is identified as a temporal increase in infection or colonisation of a specific bacterial species in a distinct population, caused by enhanced transmission. It could be caused by a single epidemic strain or a combination of strains (46). In a healthcare setting an attentive physician or 
nurse, or a laboratory worker in the microbiological laboratory is often the first to notice an unusual increase in a usual pathogen, or sporadic cases of an unusual disease. Recognition of an outbreak is the first step in harm limitation. The most important reason to start an investigation of an outbreak is to identify and eliminate any source in order to prevent further cases (47). Since not every transmission of pathogenic bacteria results in an infection, there could be widespread distribution of a microbial agent before it results in a symptomatic infection. This results in non-identifiable potential sources for a new outbreak, for example the discovery of asymptomatic carriers found in MRSA outbreaks or in outbreaks of Enterobacteriaceae with ESBL (48-51). In outbreaks of ESBL-EBC and MRSA, the infectious agent is a common pathogen with a striking feature (in these cases the antibiotic resistance pattern) that catches attention, and results in complementary epidemiological typing. Spread of common pathogens with no striking feature rarely leads to epidemiological typing. Consequently small outbreaks of common pathogens with no striking features probably pass by without recognition.

\section{Outbreak interventions}

The main principle of coping with outbreaks in the healthcare setting is to identify the causative agent and its way of transmission and, if necessary, revise antibiotic routines. The aim of hygiene measures is to prevent transmission, without knowing whether a patient is harbouring pathogens or not, by assessing each individual for risk-factors that facilitate transmission (e.g. wounds, diarrhoea, exposure to chicken pox etc.)(52).

\section{Basic hygiene guidelines}

In Sweden, efforts to curb healthcare-associated infections are based on the concept of basic mandatory hygiene guidelines stipulated by the National Board of Health and Welfare.

Basic hygiene guidelines are designed to be used in all healthcare provider- patient contact situations such as patient examination, patient nursing, and treatment. The guidelines comprise the following points. 
1) Clothing should be short-sleeved.

2) Working clothes should be changed at least every day, more often if dirty.

3) Hands and forearms should be free from jewellery such as rings, bracelets and watches.

4) Regular disinfection of hands with alcohol-based disinfectants or agent with corresponding effect.

5) Disinfection of hands before and after direct contact with each patient.

6) If hands are visibly contaminated, hand-wash with water and liquid soap is recommended before disinfection.

7) After contact with a patient suffering from gastroenteritis, hand-wash with water and liquidsoap is recommended before disinfection.

8) Hands should be dry before hand-disinfection.

9) When there is a risk for contamination of working clothes with patient blood, body-fluids, secretion or excretions, disposal plastic aprons or gowns must be worn.

10) Disposable gloves must be worn when procedures carry the risk of exposure to blood, bodyfluids, secretion or excretions.

11) Disposable gloves must be removed directly after each risk moment, and must be changed between procedures.

This list complies with the evidence-based guidelines for preventing HAI in hospitals in England (2).

\section{Human pathogens and commensals}

In this thesis I have focused on certain human pathogens because they are frequent causes of infection, or are commensals as natural inhabitants in the human colon or faeces not causing infection. Serratia marcescens and enterococci were the focus of my studies as they were the cause of outbreaks. 


\section{Enterobacteriaceae}

Members of the Enterobacteriaceae family are important human pathogens and may cause urinary tract infections, gastrointestinal infections, abscesses, pneumonia, and meningitis. They are glucose fermentative gram-negative rod shaped, and are well represented in the human gastrointestinal tract. Enterobacteriaceae account for nearly $50 \%$ of septicaemia cases, more than $70 \%$ of urinary tract infections, and a significant percentage of gastrointestinal infections(53). Escherichia coli may cause infection in both normal and compromised hosts and is the most common cause of urinary tract infections and septicaemia in the healthcare setting, and is a common agent of intra-abdominal infections (54). Other clinically important members of Enterobacteriaceae group, causing extraintestinal infections are Klebsiella, Enterobacter, Serratia, Proteus, Providentia, Morganella and Hafnia(54). The three first-mentioned are often involved in outbreaks of $\mathrm{HAI}(55,56) . S e r r a t i a$ marcescens has constitutional resistance genes and thereby the ability to develop resistance to cefalosporins and penicillins during treatment. S. marcescens is a natural inhabitant of soil and water and sometimes found in the human gastrointestinal tract $(57,58)$

\section{Pseudomonas, Stenotrophomonas and Acinetobacter}

Important human pathogens in this group are $P$. aeruginosa, $S$ maltophilia and $A$ baumanni. These bacteria are opportunistic bacteria that cause infections in the compromised host, often seen in patients at burn units, NICU and ICU. They have intrinsic antibiotic resistance that makes infections difficult to treat.(53) P. aeruginosa and $A$ baumanni can survive long time in a moist environment and several outbreaks of HAI with are described.(59-63)

\section{Pseudomonas, Stenotrophomonas and Acinetobacter}

Important human pathogens in this group are P. aeruginosa, S. maltophilia and A. baumanni. These bacteria are opportunistic bacteria that cause infections in the compromised host, often seen in patients on burn units, NICUs and ICUs. They have intrinsic antibiotic resistance that makes 
infections difficult to treat (53). P. aeruginosa and A. baumanni can survive long periods of time in a moist environment and several outbreaks of HAl have been described (59-63).

\section{Enterococcus, Staphylococcus and Streptococcus}

Enterococci are gram-positive facultative anaerobic bacteria that are natural inhabitants of the gastrointestinal and genito-urinary tracts in humans. They can grow and survive for a long time in harsh environments. Enterococcus faecalis and Enterococcus faecium are frequently found as opportunistic pathogens. Severe infections such as endocarditis and bacteraemia with high mortality rates are not unusual. Enterococci are intrinsically resistant to the inhibitory and bactericidal activities of many commonly used antimicrobial agents, including some beta-lactam antibiotics (53). Resistance to vancomycin and high levels of aminoglycosides is an increasing problem and multi-drug resistant enterococci have emerged as an important cause of healthcare-associated infection (64). Healthcare-associated infection with enterococci is either endogenous or the effect of indirect contact between patients via staff or through medical devices. A contaminated environment may facilitate the spread. A number of investigators have sampled environmental surfaces in units where infected or colonised patients are located $(20,65)$. Inanimate objects as diverse as electronic rectal thermometers $(66)$ and air-fluidised microsphere beds $(67,68)$ have been implicated in the transmission of E. faecium.

S aureus is an important pathogen causing skin diseases such as folliculitis and furunculosis, surgical site infections, abscesses, osteomyelitis, pneumonia and sepsis etc. (54). Approximately $20 \%$ of a population are nasal carriers of $S$ aureus and numerous other sites are colonised such as the axillae, groin and gastrointestinal tract. This provides a reservoir from which endogenous as well as exogenous spread may occur (69). 


\section{Anaerobic bacteria}

In clinically significant anaerobic infections, there is often a mixture of species involved and the relevance of each bacterium is difficult to evaluate. In this thesis they are regarded as members of the human faecal microbiota and are presented in the section on faecal flora. Anaerobic bacteria are often found in abscesses and other intra-abdominal infections (54).

\section{Antimicrobial agents and antibiotic resistance}

Since Alexander Fleming discovered the antibacterial properties of penicillin in $1927(70,71)$, antimicrobial agents have been used in treating infections and as infection prophylaxis in surgery. The importance of antimicrobial agents in many advanced medical interventions such as organ transplantation, cancer treatment and prosthetic surgery is considerable (72). Development and commercial availability of new antibiotics are closely followed by development of resistance among microorganisms. Early examples of this were sulphonamide-resistant Streptococcus pyogenes in military hospitals in the 1930s and penicillin-resistant Staphylococcus strains in 1948 (73). Holmberg et al estimated that infection caused by an antibiotic-resistant bacteria doubles the duration of hospital stay, double the mortality, and probably the morbidity, compared with infection with corresponding antibiotic-susceptible infections (74). Bacterial resistance occurs through intrinsic or acquired mechanisms. Intrinsic mechanisms are those naturally occurring in the bacterial chromosome where some beta-lactamases and antibiotic efflux systems are examples. Acquired mechanisms occur as mutations in genes targeted by the antibiotics, or exchange of transferable mobile genetic elements (75). In the following paragraphs antibiotics used in the studies in this thesis are briefly presented with mode of action, antibacterial spectrum and elimination.

\section{Beta-lactams}

One of the largest groups of antibiotics is the beta-lactams comprising penicillins, cefalosporins, carbapenems and monobactams. Beta-lactam antibiotics are characterised by beta-lactam ring structure, which is essential for their antibacterial effect. Their action is to inhibit cell wall synthesis by binding to penicillin-binding-proteins (PBP) and block cell wall assembly. Resistance to beta-lactam 
antibiotics is gained via four mechanisms; hydrolysis of the beta-lactam ring by beta-lactamase enzymes; reduction in penetration of the antibiotic through the lipopolysaccharide membrane to the PBP; enhanced efflux of the drug from the periplasmatic space; and alteration in PBP structure target resulting in reduced binding affinity.(54)

One important emerging group of beta-lactamases are the extended spectrum beta-lactamases (ESBL), where the gene for beta-lactamase production is sited on mobile genetic elements. These mobile genetic elements can cross bacterial species boundaries. ESBL production leads to degradation of cefalosporins beta-lactam (76) and recently carbapenem beta-lactam (77).

Penicillins: the penicillin group includes natural penicillins (e.g. penicillin G), penicillin $\mathrm{V}$, penicillinase-stable penicillin (e.g. isoxasolyl-penicillin), aminopenicillins (e.g. ampicillin) and ureidopenicllins (e.g piperacillin) (54). Common clinical uses of penicillin include treatment of infections with Streptococcus pyogenes, and susceptible strains of Streptococcus. pneumoniae. Penicillinase-stable penicillins (e.g isoxasolyl-penicillin) are used to treat methicillin-sensitive Staphylococcus infections. Aminopenicillins (e.g.ampicillin) and ureidopenicillins (e.g. tazobactam) have the same spectrum and in addition are activie against Neisseria, Haemophilus influenzae, some Enterobacteriaceae spp, and to some extent $E$. faecalis. The combination of ampicillin or piperacillin with the beta-lactamase inhibitor clavulanic-acid and tazobactam respectively (inhibitor of Amber class A beta-lactamases), extends the antibacterial spectrum of these penicillins. The piperacillintazobactam combination is used in treating infections caused by $P$. aeruginos $a$ and also has effect against some ESBL-producing strains of E. coli and Klebsiella spp as well as an effect on anaerobes. Penicillins are mainly eliminated through the kidneys, but a small fraction is secreted in the bile (78). In the case of piperacillin-tazobactam the fraction excreted in the bile, is probably less than $5 \%(79)$. Cefalosporins: The cefalosporins form a large group with various antibacterial spectra. Due to low toxicity and broad spectrum they are widely used to treat infectious diseases in almost all areas (54). Cefuroxime is active against streptococci and staphylococci (e.g. penicillin-sensitive S. pneumoniae, S. 
agalactiae and methicillin-sensitive S. aureus) and are effective against gram-negative bacteria (e.g. E. coli, K. pneumoniae, P. mirabilis, H. influenzae)(80). Cefotaxime is active against the same bacteria as Cefuroxime, but has better activity against Enterobacteriace, including Salmonellae spp and Shigellae spp(80). Ceftazidime has good activity against Enterobacteriaceae, P. aeruginosa, $H$. influenzae and Neisseria spp, its activity against Staphylococci and Streptococci is poor(80). Enterobacter spp, Citrobacter spp, Serratia spp, Morganella spp and Providentia spp are able to develop resistance against cefalosporins during treatment. The mechanism of this "resistance development during treatment" is either up-regulation of existing beta-lactamase production or spontaneous mutation $(81,82)$. Cefuroxime, cefotaxime and ceftazidime are mainly and rapidly excreted by the kidneys with only a very small fraction secreted in the bile where the concentration is even lower than the plasma concentration (83-85). An exception to this is Ceftriaxone that is slowly excreted by the kidneys with as much as $40-50 \%$ of a dose is recovered in the faeces $(2,84)$

Carbapenems and monobactams: Carbapenems (e.g. imipenem, meropenem, ertapenem) bind to the PBP of gram-positive and gram negative organisms with high affinity. In gram-negative organisms they are transported via a specific outer membrane protein (OrpD) and have excellent betalactamase stability. Their antibacterial activity against gram-positive bacteria as well as gramnegative bacteria is broad and they even have a well-documented anaerobe effect. Imipenem and meropenem are often used in serious and life-threatening infections. Carbapenems often have effect against ESBL or AmpC-carrying Enterobacteriaceae with the exception of the emerging problem with ESBL CARBA.(77) Resistance against Imipenem in Pseudomonas spp and Acinetobacter spp is due to loss of or reduction of outer membrane protein (OrpD) or beta-lactamase production. In $P$. aeruginosa efflux pumps also cause imipenem resistance (78).

Aztreonam is a monobactam, only used in this thesis as a diagnostic disk in cultures, since it is only active against gram-negative aerobic bacteria (54). 
Carbapenems are predominantly excreted by the kidneys, but a small fraction is secreted in the bile in a microbiologically active form and passes the gut. About $1-2 \%$ of the dose of meropenem administrated is found in the faeces(86) but $10 \%$ of ertapenem is found in the faeces (87)

\section{Fluoroquinolones}

The action of quinolones (e.g. ciprofloxacin) is by blocking DNA gyrase or topoisomerase and there by transcription of DNA inhibiting bacterial growth. Ciprofloxacin has activity against Enterobacteriaceae spp, P. aeruginosa, Acinetobacter spp, Campylobacter spp, Aeromonas spp, Vibrio cholerae, $H$. influenzae, Moraxella catarrhalis, Legionella pneumophila, Neisseria spp and Pasteurella multocida(80). Ciprofloxacin also has activity against gram-negative anaerobic bacteria (78). Clinically important resistance to fluoroquinolones is due to mutations in the bacterial DNA gyrase and/or topoisomerase IV(88). Ciprofloxacin is eliminated via the liver and kidneys (78). After intravenous administration about $15 \%$ of the Ciprofloxacin dose is found in the faeces and $60 \%$ in the urine $(80,89)$, after oral administration about $11-30 \%$ of the dose is found in the faeces $(90)$.

\section{Aminoglycosides}

The aminoglycosides inhibit protein synthesis by blocking the large subunit, $30 \mathrm{~s}$, of the bacterial ribosome(78) . Aminoglycosides( e.g. gentamicin, tobramycin) have good antibacterial activity against Staphylococci spp, Enterobacteriaceae spp, Pseudomonas spp and Acinetobacter spp (91).

Resistance to aminoglycosides is due to a large number of aminoglycoside-modifying enzymes. The genes of such enzymes are often found on integrons and other mobile genetic elements. Acetyltransferases, for example are capable of modifying tobramycin, gentamicin, netilmicin and amikacin. Nucleotidyltransferase alters the activity of tobramycin, and phosfotransferase affect amikacin susceptibility (75). Gentamicin is mainly excreted by the kidney, but a small fraction is secreted in the bile and the mean biliary concentration is usually $30-40 \%$ of the serum concentration (92). 


\section{Sulphonamides and Trimethoprim}

Sulphonamides and trimethoprim act on dihydropteroate synthetase and dihydrofolate reductase respectively, in prokaryotic cells thereby disrupting the purine synthesis. Purine is the building block of RNA and DNA. Trimethoprim-sulphamethoxazole is a combination with activity against Staphylococcus spp, Streptococcus spp including S. pneumoniae, E. coli, Klebsiella spp, Enterobacter spp, Proteus spp, Salmonellae spp, Shigellae spp and Stenotrophomonas maltophilia among others $(80)$. Resistance is due to mutations in the enzyme gene reducing the substance's affinity for the enzymes and by a reduction in purine synthesis inhibition (75). Trimethoprim-sulphamethoxazole is also mainly excreted by the kidney and the concentration of trimethoprim in bile is slightly higher than in serum (93).

\section{Nitroimidazoles}

Metronidazole has activity against a variety of anaerobic bacteria, micro-aerophilic bacteria and protozoa e.g. Bacteroides spp, Prevotella spp, Fusobacterium spp, Porphyromona spp and Peptostreptococcus spp (78). The antibacterial and antiprotozoal effect is due to the cytotoxic activity of free radicals (54). Metronidazole is largely excreted by the kidneys, only $13.9 \%$ is found in the faeces (94). When given parenterally metronidazole penetrates well into inflamed intraabdominal organs (95) and when given as prophylaxis preoperatively a high concentration in colonic wall tissue is achieved that is maintained through-out surgery(96).

\section{The faecal flora}

The human gut flora is a large dynamic bacterial community, an adult bacterial flora is considered to harbour about $10^{14}$ microbes, that is ten times the number of cells in the adult human body(97).The community of microorganisms residing or passing the gut could also be referred to as the gut microbiota (98). This thesis focuses on the bacterial content of the microbiota, and the concept microbiota is used to describe the results from 16sRNA gene sequencing. If one considers the different bacterial species in the gut flora as different cell lineages with the capacity to communicate 
with one another, the capacity to consume, store and redistribute energy, and the capacity to maintain and repair itself through self-replication, the gut flora may well be regarded as being a microbial organ (99). The majority of gut microbes reside in the large intestine and rectum, where the environment is suitable for a large variety of microorganisms. The gut flora contributes to the body's metabolism by fermentation of non-digestible dietary residues and endogenous mucus. It also salvages energy from fatty acids and produces vitamin $\mathrm{K}$ and facilitates the absorption of ions (100). One fatty acid produced in the colon is butyrate, an important energy source for the colonic epithelium (101). The faecal flora also has a protective effect against pathogens, by taking space and producing antibacterial substances and play an important role in the maturation of the human immune system (100).

Colonisation of the human gut with microbes starts immediately after birth. The number of species and the diversity increases during the first year of life. The composition of the flora is influenced by the maternal colonisation, diet, environmental exposure and any antimicrobial therapy (102). It is presumed that this initial colonisation is important in shaping the composition of the gut flora in the adult individual. After the first year of life the microbiota stabilises and resembles that of a young adult. Comparison of faecal samples from monozygotic twins living apart, their marital partners and unrelated individuals implicate that host genotype is of greater impact than the diet in determining the microbial composition of the gut microbiota (103).

Collecting samples from the large intestine is complicated. When collecting samples during gut surgery, the patient is anaesthetised, often has an intestinal disease that has led to the procedure, and has received antibiotics as preoperative prophylaxis. A preferable way of collecting samples is through an endoscope, but this often requires laxative treatment before the procedure, and isn't always suitable in the acutely ill patient, and probably affects the microbiota. Another problem is to maintain an adequate anaerobic sample milieu pending culture, since the vast majority of the 
microbiota is anaerobic. Most studies on the colonic bacterial content is performed on faecal samples, studies have shown that the bacterial composition of the large intestine and of faeces is similar (104).

Bacterial genera (groups) in cultured human faeces samples are dominated by the obligate anaerobic genera Bacteroides spp, Eubacterium spp (and former members of the genus) and Bifidobacterium spp. The facultative aerobics are dominated by Enterobacteriaceae spp, Enterococcus spp and Streptococcus spp. Other genera found are Prevotlella spp, Clostridium spp, Fusobacterium spp, and gram-positive anaerobic cocci, Rumniococcus spp, Lactobacillus spp, Actinomyces spp and Propionebacterium (104).

In 16S rRNA gene studies so far, Firmicutes and Bacteroidetes dominate the colon microbiota. Less than $5 \%$ consist of Proteobacteria, Actinobacteria and other phyla together (105).

\section{Bacterial classification and nomenclature}

To compare the results between the different methods in my thesis, some bacterial classification and nomenclature aspects should be taken into account.

Early classification systems used morphological, physiological and biochemical criteria to delineate the species of bacteria, these being the typing techniques available at that time. This shows the phenotypic features with no regard of evolutionary relationships. The basic unit in this system was the species. During the 1980's molecular biology developed rapidly, DNA-DNA hybridisation of whole bacterial genomes and sequencing of the $16 \mathrm{~s}$ or $23 \mathrm{~s}$ RNA-gene led to a new dimension in taxonomy. Vandamme et al. proposed the term polyphasic taxonomy to approach bacterial classification (106). Polyphasic taxonomy is a synthesis of chemotaxonomic and phenotypic features with phylogeny derived from 16S RNA gene analysis, in consensus. One classification work often referred to is Bergey's Manual of Systematic Bacteriology (107), where this concept is used. 
There is no official classification of bacteria but an official nomenclature. Since 1980 priority of bacterial name is based on the approved list of bacterial names (12) and new names are only accepted if they are published in the International Journal of Systematic and Evolutionary Microbiology (IJSEM), published by the Society for General Microbiology (SGM). This is the official journal of bacterial names of the International Committee on Systematics of Prokaryotes (ICSP) of the International Union of Microbiological Societies (IUMS). Prior to 1980, because of the great diversity of bacterial species, duplicity of new species occurred when they were published in different journals using different names at different times. There are also bacteria that cannot be cultured and are thus characterised by microscopic morphology or by differences in molecular sequence.

All living cells are divided between the three domains; Bacteria, Archeae and Eucarya. The domain Bacteriae is divided into 23 phyla which are subdivided into 28 classes. Three important phyla containing a great number of clinically relevant bacterial species in humans are Proteobacteria, Firmicutes and Actinobacteria. Other phyla of importance in the human are Bacteroidetes, Chlamydiae and Spirochetaetes.

Proteobacteria includes the majority of gram-negative bacteria such as the families: Brucella, Erlichia and Rickettsia (Alphaproteobacteria); Burkholderia, Bordetella and Neisseria (Betaproteobacteria); Aeromonas, Legionella, Vibrio and Enterobacteriacae (Gammaproteobacteria); Campylobacter and Helicobacter (Epsilonproteobacteria).

Firmicutes are gram-positive organisms including Bacillus, Clostridium, Staphylococcus, Mycoplasma, Enterococcus, Streptococcus and Lactobacillus.

Actinobacteria are gram-positive organisms including Bifidobacterium, Mycobacterium and Corynebacterium. The phyla Bacterodietes include Bacterodies, Flavobacterium and Sphingobacteria (53). 
Identification of bacteria at a routine microbiology laboratory is often limited to biochemical tests and standard molecular typing procedures such as 16s rRNA gene PCR with comparison of characteristics to reference types.

\section{Culture methods}

During cultivation, bacteria in bacterial samples multiply under different circumstances. Typing is based on phenotype properties such as the ability to grow on various culture media (using different substrate for energy harvesting), antibiotic -susceptibility, growth in various oxygen concentrations or with carbon dioxide in the micro-atmosphere, and the result of gram-staining amongst others (53). With these culture methods the phylogenetic information obtained is minimal and epidemiological information limited.

\section{Molecular typing methods}

Molecular typing of bacteria is usually based on 3 consecutive procedures:

1) Amplification of a selected region of the bacterial chromosome using PCR

2) Sequencing of the amplified segment

3) Searching for a similar sequence in a reference nucleotide sequence database(53)

\section{PCR}

The polymerase chain reaction (PCR) is a well-established method for multiplying selected DNA sequences. It is based on DNA synthesis driven by a thermo-stable DNA-polymerase as primer for the extension reaction. Apart from DNA-polymerase and a double-stranded template DNA, a mixture of nucleoside triphosphates and two synthetic oligonucleotides with known sequences (the primers) are required. One primer must be complementary to the $3^{\prime}$-end of the + (plus) strand of the intended amplification segment of the DNA template. The other primer must, correspondingly, be complementary to the $3^{\prime}$-end of the - (minus) strand of the template. In the first step of the PCR reaction the temperature is raised above the denaturation temperature of double-stranded DNA $\left(\sim 95^{\circ} \mathrm{C}\right)$. The template then becomes single-stranded. In the next step the temperature is lowered to 
$\left(\sim 60^{\circ} \mathrm{C}\right)$ so that the primers can anneal with the corresponding complementary sequences on + and strands of the template, respectively. The DNA-polymerase then starts synthesis of a new strand of DNA that is complementary to the template sequence by extending the $3^{\prime}$-end of the primer. Only nucleotides that are complementary to the template DNA strand will be incorporated.

Pyrophosphate is released in the reaction. The high temperature - low temperature cycle is repeated many $(25-50)$ times, and for each cycle the number of DNA copies (PCR products or amplicons) doubles (108). Twenty cycles will produce a million copies from each template DNA molecule. The PCR reaction is thus capable of producing sufficient amounts of DNA for sequence analysis even if there were only a few DNA molecules in the sample to start with. The full-length DNA of a bacterium could be used for typing and phylogenetic studies but it is a large molecule and is too time and resource consuming at present. Selected regions of the DNA coding for the small subunit of the bacterial ribosome (16s rRNA) has proved useful in both phylogenetic studies as well as classification at family or even species level (109). The 16S rRNA gene is about $1550 \mathrm{bp}$ long and has a variety of well-conserved regions and regions of hypervariability. The gene polymorphism and the size of the 16S rRNA gene provide a distinguishing and statistically valid measure for bacterial identification (109).

By targeting highly conserved regions with -primers, multiplying and sequencing the highly variable regions of the 16S rRNA gene, and comparing the results with a reference gene database, identification of family or species is possible.

\section{Pyro-sequencing of the PCR product}

Pyrosequencing is a widely used technique for determining the order of nucleotides in a DNA strand. It is based on sequencing a single strand of DNA by the synthesis of a complementary strand as primer extension. In this reaction, the four nucleoside triphosphates (dATP, dCTP, dGTP, and dTTP) are dispensed one at a time in a predetermined order to the reaction vessel, while one monitors the release of pyrophosphate indicating incorporation of the added base. If the dispensed nucleotide is not complementary to the template it will not be incorporated into the newly synthesised DNA 
strand and no pyrophosphate will be released. The excess of dispensed nucleoside triphosphate is degraded by the enzyme apyrase before the next base is added for synthesis.

Pyrosequencing may briefly be described in 6 steps.

1. One strand of the PCR product to be sequenced is used as template and hybridised to an oligonucleotide primer. The choice of primer determines the starting point for DNA synthesis. If the whole PCR product is to be sequenced the corresponding PCR primer would be appropriate.

2. The process begins with dispensation of the enzymes: DNA-polymerase, needed for synthesis; apyrase, a nucleoside triphosphate degrading enzyme; and two enzymes used for the detection of pyrophosphate release by giving a chemiluminescent signal. In the next dispensation the substrates adenosine 5' phosphosulphate (APS) and luciferin are dispenced to the reaction vessel, which then contains all the requirements for DNA synthesis apart from deoxynucleoside triphosphates. Thereafter, dATP, dCTP, dGTP, and dTTP are dispensed one at a time in a predetermined order (e.g. cyclical A, C, T, G, A, C, G, T ...). Actually, dATP $\alpha$ S, which is not a luciferase substrate, is added instead of dATP.

3. If the nucleotide added is incorporated into DNA pyrophosphate is released.

4. The released pyrophosphate is converted to ATP in the presence of APS by the enzyme ATPsulphurylase, providing energy for Step 5.

5. Light is emitted when oxidation of Luciferin is catalysed by Luciferase. The reaction is driven by ATP as the energy source.

6. The light signal is monitored in real-time and correlated with the nucleotide introduced. The signal amplitude is proportional to the amount of nucleotide incorporated. Thus a homopolymer e.g. AA in the nucleotide sequence will appear as a double strength peak 
signal. However, the proportionality is not absolute. This makes it virtually impossible to determine the exact length of longer homopolymer sequences e.g. AAAAAA in DNA, which is a weakness of the pyrosequencing method (110) .

\section{DNA sequence databases}

Frequently used DNA sequence databases from known bacterial isolates and well-characterised reference strains, as well as bacteria that cannot be cultured are GeneBank (111) , Greengene (112) and RDP-II( Ribosomal Data Project II)(113), where the last two focus on rDNA genes. BLAST (Basic Local Alignment Search Tool, National Library of medicine, US) $(114,115)$ is a tool for matching the DNA sequence to a known species or family.

\section{UniFrac}

UniFrac is a method used for computing differences between microbial communities based on DNAsequence data (116). UniFrac is a beta-diversity measure that uses phylogenetic information to compare environmental samples. When used with standard multivariate statistical techniques including principal coordinate's analysis (PCOA), it identifies factors that explain differences between microbial communities (117). Such methods are valuable when searching for gradients that affect microbial distribution; gradients could be human disease states (118).

\section{Pulsed-field gel electrophoresis}

In pulsed-field gel electrophoresis (PFGE), the whole DNA content of a bacterial isolate, is exposed to a defined restriction endonuclease with six or more base pair recognition sites. The cleavage usually results in fewer than 30 fragments in the size range 20 to $600 \mathrm{kbp}$. These fragments are separated on an agarose gel by periodically altering the angle of an electric field. The patterns of the DNA fragments are digitalised and computer analysed. PFGE provides isolate-specific bacterial fingerprints 
(46). PFGE is resource- and time- consuming; the process takes 2-4 days. Two isolates with no observed difference in PFGE patterns are considered to be indistinguishable, and probably from the same origin within a relevant time span (clone). Isolates differing by one to four bands are considered to be subtypes (46) or, if there is a relevant space and time span, closely related and probably part of the same outbreak (119). When interpreting epidemiological typing results it is important to regard the result in it's time-frame and current epidemiological context. It could also be of interest when comparing current outbreak isolates with previous ones. Epidemiological typing can be helpful when tracing the source or way of transmission of bacteria. PFGE has a high discriminatory power and reproducibility, and is suitable for almost all bacterial species (46). 


\section{Aims}

The aims of the thesis were:

- To perform an epidemiological investigation of enterococcus septicaemia clustering (Paper I) and Serratia marcescens sepsis clustering (Paper III).

- To evaluate the impact of outbreak interventions (Papers I and III).

- To investigate changes in the rectal flora and the emergence of antibiotic resistance in Enterobacteriaceae and non-fermentative gram-negative bacteria, in patients with intraabdominal infection receiving antibiotics (Paper II).

- To study risk factors for Serratia marcescens septicaemia (Paper III).

- To investigate the microbial diversity of the microbiota of patients suffering from appendicitis or diverticulitis, and the microbial dynamics after antibiotic therapy and hospitalisation. (Paper IV) 


\section{Material and Methods}

\section{Study designs}

Paper I was an open retrospective descriptive study.

Paper II was an open prospective observational study.

Paper III has two parts, one was an open retrospective observational study and the other was a retrospective case-control study.

Paper IV was an open prospective observational study.

\section{Settings}

Papers I and III were conducted on a general intensive care unit (GICU) and a neonatal intensive care unit (NICU), respectively, at the University Hospital in Linköping (UHL). UHL is a tertiary care university-affiliated 780-bed teaching hospital and serves a region in the southeast of Sweden with around 1 million inhabitants. The hospital's intensive care is divided into the GICU, the NICU and several subspecialised ICUs; burn ICU, coronary care unit, neurosurgical ICU, and thoracic surgery ICU, where patients often have critical single organ conditions.

The GICU serves all medical and surgical departments in the hospital and gives care to patients with a range of diseases or multiple critical conditions, including neurosurgical and cardiopulmonary diseases, and children, other than neonates. At the time of the study, 800-950 patients were admitted per year. Approximately $15 \%$ were trauma patients and $25 \%$ were other emergency admissions. Less than $10 \%$ of patients were admitted for planned postoperative intensive care after extensive surgery. The GICU mortality was $4.7-5.5 \%$.

The NICU provides care to approximately 450 infants per year. The unit consists of six to seven cots for full intensive care with ventilation and CPAP treatment, and eight cots for treatment of preterm infants born between 28-32 gestational weeks for treatment of jaundice, feeding problems etc. Most 
pregnant women within the region, at risk of delivery of infants born before 29-30 gestational weeks, are referred to Linköping University Hospital. Infants admitted to the NICU are between 23 weeks of gestation to three months of age. About 60 patients need ventilation care and 120 patients need continuous positive airway pressure (CPAP) per year. Between 2006 and 2011; $20( \pm 3)$ infants prior to gestational week 27 (extremely preterm) were born. In the Express study from Swedish NICUs, survival to discharges is $72 \%$ and the incidence of sepsis is around $40 \%(5)$.

In Papers II and IV, surgical emergency wards and surgical units from eight hospitals in the mid and south-east regions of Sweden participated; hospital in Norrköping, Västerås, Gothenburg, Örebro, Helsingborg, Uppsala, Linköping and Karlstad.

\section{Identification of outbreak}

In Paper I, the outbreak was first noticed by workers in the microbiology laboratory in January 1996. They observed enterococci in blood cultures from 5 patients within ten days, all from the same ICU, when there used to be only one case per year. The hygiene department and the ward were alerted.

In Paper III, the initial outbreak on the NICU at UHL was first noticed in January 2007 by laboratory workers when they isolated S. marcescens from a number of patients over less than a week. Cultures were from more than four patients, including one blood culture. Until 2006 S. marcescens was rarely seen on the NICU. No isolates were identified from 2003 until August 2006.

\section{Inclusion criteria cases, control and registered data}

In Paper I all patients admitted to the ICU from 1 March 1995 to 29 February 1996 were included as study population and all patients admitted to the ICU from 1 March 1996 to 29 February 1996 were included as control population. The characteristics of the two groups were compared according to individual patient disease severity assessed by the APACHE II score(120); the extent of therapeutic interventions assessed by TISS $(121,122)$; growth on microbiological cultures from the clinical 
microbiology laboratory's computer system; antibiotic consumption assessed by delivery data from the hospital pharmacy; ICU occupancy and length of stay on the ICU.

In Paper II adult patients aged eighteen and over, admitted to a surgical ward with a suspected diagnosis of complicated intra-abdominal infections requiring surgical intervention were included. Surgical diagnoses:

1) Cholecystitis (including gangrenous) and either rupture, perforation or progression of the infection beyond the gallbladder wall. Surgical intervention or CT/Ultrasound confirmed diagnosis.

2) Diverticular perforation/abscess requiring surgical intervention or $\mathrm{CT} / \mathrm{ultrasound}$ confirmed abscess without surgical intervention.

3) Perforation of appendix with local purulent fluid on surgical intervention or abscess confirmed by $\mathrm{CT} /$ Ultrasound without surgical intervention.

4) Acute gastric or duodenal perforation, only if operated on $>24$ hours after perforation occurred.

5) Traumatic perforation of the intestines, only if operated on $>12$ hours after perforation occurred.

6) Peritonitis due to visceral or other focus of infection (but not spontaneous bacterial peritonitis associated with cirrhosis and chronic ascites).

7) Intra-abdominal abscess including liver and spleen abscesses.

Data registered for the study included age, gender, inclusion diagnosis, surgical interventions, discharge diagnosis, co-morbidity, previous antibiotics and travel outside Sweden during the previous 6 months. Antibiotic therapy was chosen by the attending physician according to local guidelines and traditions. 
In Paper III all patients admitted to the NICU between 2006-01-01 and 2011-10-31 with S.

marcescens cultures, were included in the outbreak analysis. In the risk-factor study, patients with a discharge diagnosis of sepsis during the same period were included.

The sepsis diagnosis was based on the following criteria:

a. Growth in blood culture and at least 2 of criteria 1-4

b. No growth in blood culture and at least 3 of criteria 1-4

Sepsis criteria:

(1) Leukocyte particle concentration (LPK) $<5 \mathrm{mg} / \mathrm{mL}$ or $>20 \mathrm{mg} / \mathrm{mL}$

(2) Platelet particle concentration (PPK) $<100 \mathrm{mg} / \mathrm{mL}$

(3) C-reactive protein (CRP) >15 mg/L

(4) Impaired respiratory function with respiratory rate $>70$ breath per minute, grunting/gasping or increased ventilatory support in ventilated infants that could not be explained by other factors (123125).

LPK, PPK and CRP were taken within 24 hours after onset of clinical symptoms. When there were several values, the highest was chosen. Risk factors recorded were: age of gestation at birth and gestational age at onset of sepsis; birth weight; on-going ventilator treatment including nasal intermittent pressure ventilation; CPAP treatment indwelling umbilical vein and/or umbilical artery catheter and/or central venous catheter; premature rupture of membrane (PROM) and maternal fever during delivery (126).

The control case was defined as the first child admitted to the NICU for at least 48 hours intensive care, directly after each LOS-case had been admitted. When several LOS were admitted, an equal number of consecutive children admitted to the NICU for at least $48 \mathrm{~h}$ were taken as controls. 
In Paper IV a sub-population from patients in Paper II, patients with a discharge diagnosis of appendicitis or diverticulitis were investigated. Chemical laboratory parameters registered on admission were C-reactive protein (CRP) and white cell count (WCC). Current antibiotic treatment, previous antibiotics, travel outside Sweden during the previous 6 months, age and gender were recorded. Faecal samples from healthy controls were gathered randomly from individuals within the population-based randomised colonoscopy study (Popcol) (127). This cohort has previously been described in detail $(128,129)$. Briefly, the control population consisted of 33 individuals between 18 and 70 years of age, living within two adjacent parishes in Stockholm and born in Sweden ( individuals born abroad were excluded, since gut microbiota is already established during infancy(130)), and who had not been treated with antibiotics within the previous three months.

\section{Bacterial and yeast cultures}

Clinical bacterial samples cultured in Papers I and III, were taken when clinically relevant, from various sources (wounds, urine, blood, medical devices, tracheobronchial, secretions etc.). In Paper III screening samples for S. marcescens, were taken from the nose or throat and perineum or rectum on admission, once a week and when a patient was discharged between routine screening days. Rayon swabs with transport medium (Copan, Brescia, Italy) were used.

Rectal swabs from all patients in Paper II and IV were obtained on admission (Sample 1) and 2-14 days after the end of antibiotic treatment (Sample 2). Rayon swabs with transport medium (Copan, Brescia, Italy) were used. At the laboratory the rayon swab tips were immediately cut off and immersed in $1.0 \mathrm{ml}$ of freeze broth (Nutrient broth, No 2, Lab m Bury, United Kingdom, containing glycerol $15 \%$ ) in a sterile glass tube and shaken thoroughly. The freeze broth was transferred to a plastic storage tube and stored at $-70^{\circ} \mathrm{C}$ pending analysis. At analysis the samples were thawed and once again shaken. The rayon swab was streaked over a chromogenic UTI-agar plate (Oxoid, Basingstoke, United Kingdom) and streaked over a second UTI-agar plate using a dish rotator (131). To facilitate identification of different species, antibiotic discs (ampicillin aztreonam, ceftazidime, 
cefotaxime and linezolid) were placed on one of the plates. After overnight incubation at $35^{\circ} \mathrm{C}$, different bacterial colonies were identified visually. Bacterial isolates considered to be different species or subspecies were identified at species or family level using standard biochemical methods (53). $25 \mu \mathrm{L}$ of the freeze medium were cultured in Yeast-nitrogen-base- broth (BD, Franklin Lakes, New Jersey, USA) with gentamicin 50mg/L and chloramphenicol $50 \mathrm{mg} / \mathrm{L}$ (YNB-broth) and incubated at $35^{\circ} \mathrm{C}$ until growth or for a maximum of five days. The YNB-broth was streaked over a Sabouraudagar plate with chloramphenicol $50 \mathrm{mg} / \mathrm{L}$ and gentamicin $50 \mathrm{mg} / \mathrm{L}$ and cultured two days at $35^{\circ} \mathrm{C}$. Colonies growing on the plate were visually inspected and classified as Yeasts after gram staining and microscopy.

Environmental cultures in Papers I and II were taken, using pre-moistened rayon swabs or convex 6 $\mathrm{cm}$ trypticase soy imprint-agar-plates, from medical devices and surroundings wherever persistent $S$. marcescens or enterococci were suspected. In Paper III over 200 environmental cultures were taken from stethoscopes, laryngoscopes, thermometers, clean pacifiers, liquid soap, baby oil, ultra-sonar gel, water for incubator humidification, clean articles from the washer-disinfector, resuscitation table, computer keyboard, portable phones, clean laundry, breast pumps, incubators, hands of nursing staff and neonatologists, faecal samples of nursing staff and neonatologist, surfaces in patients room and milk kitchen and surfaces in the delivery room at the operating theatre. The environmental samples and rectal/perineum samples from the staff were analysed using standard biochemical tests (53).

\section{Antibiotic susceptibility testing}

Antibiotic susceptibility testing was performed by disc diffusion with or without MIC (Etest AB Biodisk, Solna, Sweden) using methods, breakpoints and sets of antibiotics according to guidelines of the Swedish Reference Group for Antibiotics (SRGA). The isolates were classified as sensitive (S), intermediate (I) or resistant (R). 
In Paper II isolates defined as I or R showed decreased susceptibility. All aerobic gram-negative rods were tested with imipenem, ceftazidime, ciprofloxacin, gentamicin and piperacillin-tazobactam. Enterobacteriaceae were further tested with cefuroxime, cefotaxime and trimethoprimsulphamethoxazole. The dominant bacterial population and also subpopulations of Enterobacteriaceae and non-fermentative gram-negative rods were tested for antibiotic susceptibility. Each species was counted once only per patient and sample when measuring distribution of species.

In order to detect emergence of resistance, several isolates per species from each patient were analysed. The occurrence of decreased susceptibility in all of the isolates for each species and patient was measured. Isolates of Enterobacteriaceae with decreased susceptibility to cefotaxime or/and ceftazidime were suspected as being producers of ESBL. Phenotypic double-strip Etest (AB Biodisk, Solna, Sweden) with cefotaxime with and without clavulanic acid, ceftazidime with and without clavulanic acid or cefepime with and without clavulanic acid were used to confirm classical ESBLenzymes such as CTX-M, TEM and SHV designated ESBL $\mathrm{A}_{\mathrm{A}}$. Etest with cefotetan with or without cloxacillin were used to confirm plasmid AmpC, designated $\mathrm{ESBL}_{\mathrm{M}}$. When the minimum inhibitory concentration (MIC) ratio of cephalosporin/cephalosporin with clavulanic acid $\geq 8$ or a phantom/deformation zone occurred, an ESBL-phenotype was considered. When the minimum inhibitory concentration (MIC) ratio of cefotetan/cefotetan with cloxacillin $\geq 8$ or a phantom/deformation zone occurred, an AmpC-phenotype was considered. Klebsiella pneumoniae isolates with phenotypic $\mathrm{AmpC}$ were considered to have a plasmid AmpC genotype. Isolates with $\mathrm{ESBL}_{\mathrm{A}}$-phenotype were genetically confirmed using PCR as described previously (132) to detect enzymes of CTX-M, and SHV and TEM genotype. E. coli isolates with AmpC phenotype were genetically confirmed by multiplex PCR according to Perez and Hanson (133) to verify plasmid mediated AmpC. 


\section{Pulsed field gel electrophoresis}

Isolates differing by more than three bands were considered to represent different strains in PFGE (119).

In Paper I eight bloodstream isolates from six patients, six isolates from other sources (from patients with bloodstream infections or other patients in the same room) and nine surveillance cultures positive for enterococci were chosen for the epidemiological study. Sma I was used as restriction endonuclease and the ethidium-bromide stained separated DNA fragments were compared visually.

In Paper III epidemiological typing was performed on S. marcescens isolates, 11 isolates from blood and 36 isolates from other sources. The isolates of S. marcescens were sent to the Swedish Institute for Communicable Disease Control (SMI) where epidemiologic typing was performed with PFGE using restriction endonuclease Xba 1. The results were compared with all other S. marcescens isolates analysed at the SMI.

\section{DNA extraction, PCR and pyrosequencing}

In Paper IV, DNA from faecal and rectal samples were extracted with Ultraclean faecal DNA isolation (MoBio, Naxo ltd) from $100 \mathrm{mg}$ of each faecal sample or $100 \mu$ l freezing media for rectal samples according to the manufacturer's instructions. Final elution was made with $2 \times 50 \mu l$ elution buffer (solution S5). For each sample, three $50 \mu \mathrm{l}$ PCR mixes were prepared containing $1 \mathrm{X}$ PCR buffer, 200 $\mu \mathrm{M}$ dNTP PurePeak DNA polymerase (Pierce Nucleic Acid Technologies, Milwaukee, USA), $50 \mathrm{mM}$ of each primer, $0.5 \mathrm{U}$ Phusion F-530L enzyme (Finnzyme, Massachusetts, USA) and $1 \mu \mathrm{L}$ template DNA.

Primer pairs used to amplify the hypervariable 16 rRNA regions V3-V4 were 341f (5'CCTACGGGNGGCWGCAG) with adaptor B and 805r, (5' GACTACHVGGGTATCTA ATCC) with adaptor A, and a sample specific sequence tag of 7 nucleotides as described previously (134). A PCR-negative template control was also made for each primer pair. The PCR conditions used were $95^{\circ} \mathrm{C}$ for 5 
minutes, followed by 25 cycles of $95^{\circ} \mathrm{C}$ for $40 \mathrm{sec}, 58^{\circ} \mathrm{C}$ for $40 \mathrm{sec}$, and $72^{\circ} \mathrm{C}$ for $1 \mathrm{~min}$, followed by a final extension of $72^{\circ} \mathrm{C}$ over 7 min the faecal samples.

The samples and the negative template control were then run on an agarose gel ( $1 \% \mathrm{w} / \mathrm{v}$ in TBE buffer) for quality control. The three PCR reactions were pooled, and for the faecal samples $45 \mu$ l of each pooled PCR reaction was purified using Agencourt AMPure beads (Beckman Coulter, California, USA) according to manufacturer's instructions with final elution in 1X TE buffer. The purified PCR products were diluted to a concentration of approximately $3 \mathrm{ng} / \mu \mathrm{l}$ before pooling them together for the multiplexed pyrosequencing. All concentrations were determined using the Qubit system (Invitrogen, California, USA) The DNA pools were finally sequenced on the 454-FLX GS-100 using a standard titanium kit (Roche 454 Life Sciences, Branford, CT, USA)(135). Due to the large number of samples, these were split into two titanium runs.

\section{Statistical and data analyses}

In Paper I the results are presented as mean and standard deviation. Statistical analysis was performed using Student's $t$-test and Fisher's exact test, a $p$-value $<0.05$ was considered statistically significant.

In Papers II and IV the aerobic cultured flora was summarised as indicator variables. The indicator variables were the presence or absence of each particular species; quantity was not taken into consideration. The gain or loss of a bacterial species was compared between Samples 1 and 2 using McNemars test and $p$-value $<0.05$ was considered significant.

In Paper II, the material was divided into a group with Enterobacteriaceae (EBC) and nonfermentative gram negative bacteria (NF). The EBC group included all Enterobacteriaceae spp and the NF group included $P$. aeruginosa, Pseudomonas spp (Pseudomonas other than $P$. aeruginosa), and Acinetobacter spp. Each combination of antibiotic and group was analysed separately. The fraction of EBC with decreased susceptibility in Samples 1 and 2 from each patient was calculated. The fraction 
of NF with decreased susceptibility in Samples 1 and 2 was calculated for each patient. The fraction of decreased susceptibility was defined as the number of species with decreased susceptibility divided by the number of species found. Finally the mean fractions of species with decreased susceptibility in the study population were compared between Samples 1 and 2 with two-way analysis of variance with time as fixed factor and patient as random factor. P values $<0.05$ were considered significant.

In Paper III continuous variables are presented as median and range (minimum-maximum), and categorical variables are presented as fractions. Differences between groups were compared with simple binary logistic regression and expressed as odds-ratio, with 95\% confidence limits, when significant. Significance level was $p<0.05$. Stepwise logistic regression was performed.

In Paper IV, sequences produced by 454 sequencing were processed with the QIIME pipeline (Quantitative Insight Into Microbial Ecology)(129). The sequences were filtered according to quality using the default parameters in QIIME. Sequences with an average quality score $<25$ or with a length $<200 \mathrm{nt}$ were discarded. The remaining sequences were trimmed to remove barcodes and primer sequences. Using the UCLUST(136) algorithm built into the QIIME pipeline, sequences were clustered at 97\% identity producing 10238 OTUs (Operational Taxonomic Unit). A representative sequence was chosen by taking the most abundant sequence from each OTU and was assigned a taxonomy using the RDP classifier (Ribosomal Database Project), also built into QIIME, with a minimum confidence of assigning a taxonomy of $80 \%$. The representative sequences were subsequently aligned against the Greengenes $16 \mathrm{~S}$ gene database using the PyNAST software (137).

Three metrics for alpha diversity were calculated; number of observed species; Chao1 for richness estimation and Shannon index for diversity. These metrics were calculated on a subset of 1210 randomly chosen sequences per sample in order to reduce diversity bias. Five samples containing fewer than 1210 sequences were thus removed from the alpha diversity comparison. Beta diversity measures were calculated on the same sub-sampling level. Using the QIIME pipeline, UniFrac 
distances were produced and used to make PCoA (Principal Coordinates Analysis) plots. To analyse diversity differences between the groups, for each metric a p-value was calculated using Wilcoxon's rank sum test in order to investigate the level of significance.

Continuous demographic variables are presented as median and range (minimum-maximum), differences between two groups were analysed using the Mann-Whitney U-test and between three groups using the Kruskal-Wallis test. Categorical demographic variables are presented as fractions and differences between groups were analysed with Chi2-test. $p \leq 0.01$ was considered significant.

\section{Outbreak interventions}

In Paper I interventions were employed:

(1) A temporary closure of the unit with thorough cleaning and reorganisation of rooms

(2) Isolation of infected patients as far as possible;

(3) More restrictive use of antibiotics;

(4) Further education of the staff in order to ensure increased awareness of the problems of healthcare-associated infections. Moreover, improved hygienic measures were implemented in close co-operation with the hospital Department of Hygiene.

Reorganisation of rooms consisted of closure of the four-bed room and a new four-bed room with double the floor space was brought into use. This room was organised with all patients along one wall, thereby reducing the risk for healthcare-associated bacterial spread by increasing the distance between beds. The room was used exclusively for patients with no known infections. Four new single-bedded isolation rooms with a separate disinfection room and an ante-chamber were prepared. Furthermore, two additional rooms were made available, both with a separate disinfection room and an ante-chamber and with the possibility for nursing two patients in each. Antibiotic treatments were continually discussed with a consultant from the Department of Infectious Diseases. The overall aim was to reduce usage of third-generation cephalosporins and quinolones together 
with increased diversity in choice of antibiotic treatment. The length of each treatment period was decided when it commenced. The use of metronidazole instead of oral vancomycin for the treatment of colitis due to healthcare-associated Clostridium difficile was emphasised. The staff were further educated about nosocomial spread of enterococci, particularly modes of transmission. The importance of disinfection of hands with alcoholic disinfectant before and after each patient contact, the use of gloves and gowns and environmental cleaning were strongly emphasized.

In Paper III the interventions employed were, concerning; hand hygiene and use of personal protection, hospital environmental hygiene including cleaning and storage of devices and equipment; handling of indwelling venous catheters; and the distribution of patients in rooms:

1. January-March 2007

1.1. Isolation of infected/colonised infants.

1.2. S. marcescens screening of all patients on admission and once a week while on the unit

1.3. Disposal of tube feeding syringe after every meal and no re-use, instead of manual washing twice a day in-between use.

1.4. Education on basic hygiene guidelines was given to all staff on the unit.

1.5. Improved routines for cleaning of incubators, including a checklist for the procedure. All incubators were cleaned with soap and water and, after drying, cleaned with alcohol-based surface disinfectant.

1.6. Improved routines for the handling of central venous or umbilical catheters.

1.7. Infant pacifiers disposed each day. These were previously disinfected and reused.

2. October-December 2007

2.1. Compliance to basic hygiene rules were monitored each month starting in October 2007. (see below).

2.2. The staff members were not allowed to use any form of long-sleeved coat during patient care. 
2.3. New cleaning routines for the water reservoir in the incubators humidifiers, with daily cleaning and disinfection with alcohol-based surface disinfectant. These were previously cleaned twice a week.

2.4. New cleaning routines for breast pumps, including alcohol-based surface disinfectant after each use.

3. January-March 2008

3.1. Infant clothing and bed sets were sent to the county's central laundry where cleaning with a quality-assured laundry process is used, instead of being washed at the unit's disinfection room.

3.2. Documentation of the infant's cot placement on the unit in order to facilitate identification of infants at risk when a new case of S. marcescens occurred.

3.3. Pasteurisation of donated breast milk.

3.4. Separate milk kitchen staff, not taking part in patient care, working in shifts with no more than one or two persons per shift.

3.5. Updated cleaning routines around each cot including alcohol- based surface disinfection not only when a surface was contaminated but also routinely three times a day between shifts.

3.6. Minimising the use of common material between cots, including separate tables, trash bags, pencils, chairs etc.

3.7. More frequent cleaning of the parents' day-room and kitchenette, a dishwasher was installed.

3.8. Routine use of disposable plastic gowns when in contact with the incubator or bed during patient care.

3.9. Infants younger than 25 weeks gestation with an indwelling umbilical catheter were not allowed to participate in Kangaroo care (holding the infant skin-to-skin beneath clothing of the mother or father). 
3.10. One person each day was responsible for incubator cleaning.

3.11. Incubators cleaned with alcohol-based surface disinfectant after diaper change or other dirty work.

4. April-June 2008

4.1. Checklists for cleaning routines for all technical equipment with date and signature for each cleaning procedure.

4.2. First-line antibiotic treatment was adjusted according to MIC results of the $S$. marcescens isolate. See antibiotic strategy for sepsis below.

4.3. One ICU room dedicated to care of infants 27 weeks of gestation and younger, with separate staff. When the infant became 27 weeks, they were moved to another ICU room.

5. July-September 2008

5.1. New incubators, with a separate closed humidification system brought into use.

\section{Antibiotic strategy for sepsis prior to April 2008}

Benzylpenicillin in combination with tobramycin were given to all new-born infants requiring treatment for infection, and as prophylaxis to all children, regardless of gestational age, who received an indwelling umbilical vein and/or umbilical artery catheter and/or central venous catheter. It was also given as first-line therapy in sepsis. Second-line sepsis therapy consisted of cefotaxime with or without vancomycin depending on suspicion of catheter-related sepsis or not. As third-line therapy meropenem was used.

Antibiotic strategy for sepsis after April 2008

Benzylpenicillin in combination with gentamicin was given as first-line treatment and prophyxis. When symptoms of emerging sepsis occurred, and gram-negative sepsis was suspected in the extreme preterm infant, meropenem was chosen as first-line treatment. 


\section{Monitoring compliance with basic hygiene guidelines}

Seventeen to twenty members of staff were observed each month as regards compliance in the care situation; the personnel observed were unaware of being observed. The use of hand-disinfectants, use of gloves, use of plastic apron, absence of wrist watch, ring or bracelet on hand and forearm, presence of short fingernails without nail polish were all noted. If all conditions were fulfilled, then compliance with basic hygiene guidelines was considered complete. Compliance to dress code was observed and registered in the same way. Short-sleeved work dress provided by the unit, and short hair or hair prevented from falling onto the patient, were considered correct. The percentages of staff with correct compliance with basic hygiene guidelines and compliance to dress code were calculated separately. Feedback on the percentage compliance was given to the staff each month. 


\section{Results}

\section{Paper I}

Patient characteristics from the two periods were comparable with no statistically significant differences in patient age, severity of illness, mean ICU length of stay, therapeutic intensity or mortality. The mean occupancy was higher in Period 1 with $10.7 \pm 3.3$ patients treated per day compared with $8.8 \pm 2.7$ during Period $2(p<0.001)$. During the first period there were 30 patients with a total of 35 positive blood cultures, compared to 16 patients with 18 positive cultures in the second period. There was no major difference in the types of bacteria cultured in the two study periods or the percentage of patients cultured. There was a significant reduction in antibiotic consumption measured as Defined Daily Doses (DDD); 5882 DDD in the first period compared to 3752 in the in the second period $(p<0.01)$. There were no differences in DDD per ICU patient.

\section{Figure 1}

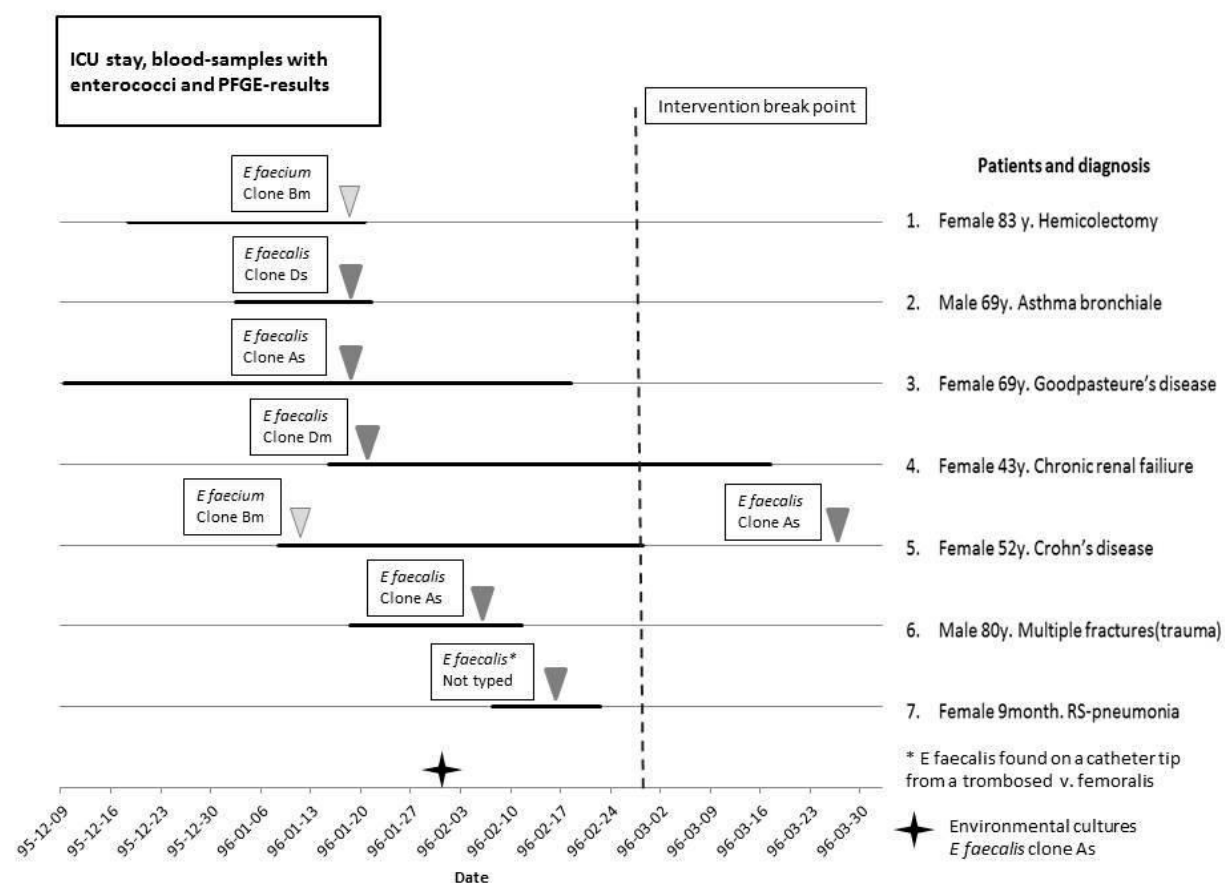


In figure 1 the ICU stay and results of PFGE on 7 blood-isolates and one catheter isolate are shown. Patients 1 and 5 had the same clone $(\mathrm{Bm})$ of E. faecium, as two patients had in bile and urine samples, respectively. Patients 3,5 and 6 had the same clone (As) of E. faecalis in blood samples and this clone was also found in three surveillance samples (from a warming-ceiling, a cleaned mattress and hands of staff). One patient had the same clone $(\mathrm{Cm})$ of E. faecium in a wound, as was found in one surveillance sample from the handle of a digital thermometer (taken approximately one month after the patient died). The remaining surveillance isolates were not found to be identical to any patient sample, but eight surveillance samples with E. faecium were of the same clone (Am).

\section{Paper II}

Samples from 140 patients ( 70 women and 70 men) were investigated in the final analyses. Surgery was performed in 83 patients (59.2\%) the most common procedure being appendectomy $(44 ; 31.4 \%)$ followed by colectomy and cholecystectomy (13; 9.3\% respectively). Fifty-seven (40.7 \%) patients were not operated upon. Eighty-two (59\%) patients had a concomitant diagnosis. Co-morbidity was dominated by hypertension 34 patients (24\%), diabetes 11 patients (8\%), malignancy 6 patients (4\%), asthma 6 patients (4\%), chronic arthritic disease 5 patients (4\%) and chronic obstructive pulmonary disease 4 patients (3\%). Twenty-seven patients (19\%) had received antibiotic treatment within six months preceding inclusion, and 34 patients (24\%) had travelled outside Sweden. Data was missing for 8 patients regarding previous travel and antibiotic treatment.

Antibiotic treatments in the carbapenem group included imipenem, meropenem and ertapenem. Correspondingly, cefotaxime, cefuroxime, ceftibuten and cefadroxil were used in the cephalosporin group. The quinolone group included levofloxacin, moxifloxacin and ciprofloxacin. 
Ninety- five of 140 patients (67.9\%) received a combination of antibiotics with frequent changes. Uniform treatment was defined as receiving antibiotics from one antibiotic class only or one combination of antibiotics the whole treatment episode. The median length of antibiotic treatment was 10 days with a range of 1 to 95 days. Of all patients, 8 (5.7\%) received a carbapenem, $8(5.7 \%)$ piperacillin-tazobactam, 23 (16.4\%) received a combination of cephalosporin and metronidazole, 4 (2.9\%) received fluoroquinolone treatment as a single treatment or in combination with metronidazole, 1 patient (0.7\%) each received a cephalosporin or a combination of cephalosporin and aminoglycoside as only treatment.

Culture results are shown in Table 1. The three most common aerobic bacteria isolated in Sample 1 were E. coli (90.0\% of all patients) followed by E. faecalis (57.9\%) and yeast (31.7\%). In Sample 2 yeast was the most common isolate (70.7\% of the patients), followed by E. faecalis (64.3\%) and E. coli (57.9\%.)

Other differences observed between Samples 1 and 2 were a decrease in P. aeruginosa $(16.4 \%$ in Sample 1 and 5.7\% in Sample 2), an increase in E. faecium (21.4 and 50.0\%, respectively) and Enterobacteriaceae not further typed (3.6 and 10.7\%, respectively).

There was a significant loss of $E$. coli and $P$. aeruginosa and a significant gain in E. faecium and yeasts between Samples 1 and 2. The group of Enterobacteriaceae, which were not identified further with routine laboratory tests, also gained in numbers. 
Table 1 Number and proportion of the 140 patients colonised with different species at the two sampling times.

\begin{tabular}{|c|c|c|c|c|}
\hline \multirow[t]{2}{*}{ Species } & \multicolumn{2}{|l|}{ Sample 1} & \multicolumn{2}{|l|}{ Sample 2} \\
\hline & $\begin{array}{l}\text { Number } \\
\text { of } \\
\text { patients } \\
\text { colonised }\end{array}$ & $\begin{array}{l}\text { Proportion } \\
\text { of patients } \\
\text { colonised } \\
\text { (\%) }\end{array}$ & $\begin{array}{l}\text { Number } \\
\text { of } \\
\text { patients } \\
\text { colonised }\end{array}$ & $\begin{array}{l}\text { Proportion of } \\
\text { patients } \\
\text { colonised } \\
\text { (\%) }\end{array}$ \\
\hline Escherichia coli & 126 & $(90.0)$ & 81 & (57.9) \\
\hline Enterococcus faecalis & 81 & (57.9) & 90 & (64.3) \\
\hline Yeast & 44 & (31.7) & 99 & (70.7) \\
\hline Klebsiella pneumoniae & 36 & $(25.7)$ & 47 & (33.6) \\
\hline Enterococcus faecium & 30 & $(21.4)$ & 70 & (50.0) \\
\hline Citrobacter species & 23 & (16.4) & 38 & $(27.1)$ \\
\hline Klebsiella oxytoca & 23 & (16.4) & 29 & (20.7) \\
\hline Enterobacter cloacae & 23 & $(16.4)$ & 21 & (15.0) \\
\hline Pseudomonas aeruginosa & 23 & (16.4) & 8 & $(5.7)$ \\
\hline Pseudomonas species & 6 & $(4.3)$ & 6 & $(4.3)$ \\
\hline Enterobacteriaceae species $^{a}$ & 5 & (3.6) & 15 & (10.7) \\
\hline Morganella morganii & 5 & (3.6) & 1 & $(0.7)$ \\
\hline Acinetobacter species & 4 & (2.9) & 7 & (5.0) \\
\hline Stenotrophomonas maltophilia & 4 & (2.9) & 4 & (2.9) \\
\hline Proteus vulgaris & 3 & (2.1) & 6 & (4.3) \\
\hline $\begin{array}{l}\text { Enterococcus species non faecium, non } \\
\text { faecalis }\end{array}$ & 3 & (2.1) & 1 & $(0.7)$ \\
\hline Enterobacter agglomerans & 2 & $(1.4)$ & 4 & (2.9) \\
\hline Proteus mirabilis & 2 & (1.4) & 3 & (2.1) \\
\hline Providentia species & 2 & $(1.4)$ & 3 & (2.1) \\
\hline Serratia species & 1 & $(0.7)$ & 4 & (2.9) \\
\hline Gram-negative bacteria $^{b}$ & 1 & $(0.7)$ & 2 & (1.4) \\
\hline Kluyrvera species & 1 & $(0.7)$ & 1 & $(0.7)$ \\
\hline Vibiro vulnificus & 1 & $(0.7)$ & 0 & $(0.0)$ \\
\hline Hafnia alvei & 0 & $(0.0)$ & 2 & $(1.4)$ \\
\hline Enterobacteriaceae species & 136 & (97.1) & 108 & (77.1) \\
\hline $\begin{array}{l}\text { Pseudomonas species /Acinetobacter } \\
\text { species }\end{array}$ & 30 & (21.4) & 21 & (15.0) \\
\hline
\end{tabular}

${ }^{\text {a }}$ Enterobacteriaceae species not further typed

${ }^{\mathrm{b}}$ Gram-negative bacteria not Enterobacteriaceae.

The gain or loss of a bacterial species was compared between Samples 1 and 2 using McNemars test.

The total number of species present was tested with the pair-wise student's t-test.

$\mathrm{P}<0.01$ was considered significant and marked as bold numbers. 
Development of antibiotic resistance is shown in Table 2. The mean fraction of Enterobacteriaceae with decreased susceptibility to cefotaxime per patient, increased from 0.357 before antibiotic treatment to 0.507 after antibiotic treatment. The corresponding figures for cefuroxime and piperacillin-tazobactam were an increase from 0.600 to 0.800 and from 0.307 to 0.450 respectively. There were no differences in the mean fraction of Enterobacteriaceae with decreased susceptibility to ciprofloxacin, gentamicin, imipenem and trimethoprim-sulphamethoxazole, per patient, before and after antibiotic treatment.

In the group of non-fermentative gram-negative rods the mean fraction of decreased susceptibility to antibiotic, per patient, decreased for imipenem from 0.043 to 0.007 . In this group there were no significant differences in antibiotic susceptibility to ceftazidime and ciprofloxacin per patient, before and after antibiotic treatment. 
Table 2 The difference in mean fraction of Enterobacteriaceae (EBC) with decreased susceptibility and Pseudomonas spp/ Acinetobacter spp (NF), between the two samples.

\begin{tabular}{l|rrr|rrr}
\hline Antibiotic & \multicolumn{3}{|c|}{ EBC } & \multicolumn{3}{c}{ NF } \\
& $\begin{array}{c}\text { Sample 1 } \\
\text { Mean }^{\text {a }}\end{array}$ & $\begin{array}{c}\text { Sample 2 } \\
\text { Mean }^{\text {a }}\end{array}$ & \multicolumn{1}{c|}{$\mathrm{p}$} & $\begin{array}{c}\text { Sample 1 } \\
\text { Mean }^{\text {b }}\end{array}$ & $\begin{array}{c}\text { Sample 2 } \\
\text { Mean }^{\text {b }}\end{array}$ & $\mathrm{p}$ \\
\hline Cefotaxime & 0.357 & 0.507 & $\mathbf{0 . 0 4 5}$ & & & \\
Ceftazidime & 0.286 & 0.379 & 0.158 & 0.043 & 0.043 & 1.000 \\
& 0.600 & 0.800 & $\mathbf{0 . 0 3 2}$ & & & \\
Cefuroxime & & & & & & \\
Ciprofloxacin & 0.414 & 0.400 & 0.841 & 0.021 & 0.021 & 1.000 \\
Gentamicin & 0.050 & 0.036 & 0.549 & & & \\
Imipenem & 0.0 & 0.014 & 0.157 & 0.043 & 0.007 & $\mathbf{0 . 0 4 9}$ \\
$\begin{array}{l}\text { Piperacillin-Tazobactam } \\
\text { Trimethoprim- }\end{array}$ & 0.307 & 0.450 & $\mathbf{0 . 0 4 1}$ & 0.014 & 0.021 & 0.640 \\
sulphamethoxazole & 0.343 & 0.293 & 0.425 & & & \\
\hline
\end{tabular}

$p<0,05$ considered significant

${ }^{\mathrm{a}}$ Mean fraction of Enterobacteriaceae $\mathrm{spp}(\mathrm{EBC})$ with decreased susceptibility to named antibiotic per patient.

${ }^{\mathrm{b}}$ Mean fraction of Pseudomonas spp/ Acinteobact $\operatorname{spp}(\mathbf{N F})$ with decreased susceptibility to named antibiotic per patient.

The mean fractions of species with decreased susceptibility in the study population were compared between Samples 1 and 2 using two-way analysis of variance with time as fixed factor and patient as random factor.

Two (1.4\%) patients had ESBL-producing E. coli in Samples 1 and 2. One (0.7\%) patient had ESBLproducing E. coli in Sample 1 only and one (0.7\%) patient in Sample 2 only. ESBL-enzymes found were CTX-M 15/28, CTX-M 14 analogous and CTX-M 3/22. Other enzymes found were TEM-1, TEM-2 and SHV-1 alike. Four (2.8\%) patients had Klebsiella pneumoniae isolates with plasmid Amp-C before 
antibiotic treatment and two (1.4\%) still had these after antibiotic treatment. No other ESBLproducing Enterobacteriaceae were found.

\section{Paper III}

Forty-seven children were colonised with S. marcescens during the study period. In March 2007, S. marcescens was found on used pacifiers after cleaning in wash-disinfector and stored in a clean box. All other environmental cultures were negative for $S$. marcescens including all 46 faecal samples from the staff. Results of the outbreak analysis are shown in Figure 2. Epidemiologic typing showed that clone A caused the two cases in 2006. In the first quarter of 2007, clone B was the cause of sepsis. In the third quarter of 2007 two children were colonised with clone B, the other 5 infants were colonised with clone $\mathrm{C}$, including the three cases of sepsis. The spread of clone $\mathrm{C}$ continued in the two first quarters of 2008 with 13 infants colonised of whom 4 developed sepsis. One child was colonised with a unique clone during the third quarter of 2008. In the first quarter of 2009 there were 13 cases with clone F, one of which developed S. marcescens sepsis. In the first quarter of 2011 there were two cases of S. marcescens sepsis among infants on another NICU after primary care on the Linköping unit. These sepsis cases occurred one and four days after discharge and had the same clone as the two colonised children at the same time on the NICU in Linköping. When these two children were admitted to the other unit they were no longer subjected to the interventions typed. The colonisation with S. marcescens, clone $U$, from the second quarter 2011 was unique. The last case in the third quarter of 2011 was colonised on admission and was not epidemiologically typed. After the major cluster of S. marcescens colonisation in the first quarter of 2009 we identified a breakpoint of colonisation even though there was a minor spread in the first quarter of 2011. The last intervention was adopted during the second quarter of 2008.

Compliance with basic hygiene guidelines was initially low with $65 \%$ compliance the fourth quarter of 2007. This increased gradually to above $80 \%$ in the first quarter of 2009 since when it has remained the same. Observations from May 2008, and May, September and November 2009 are missing and not included in those quarters. 
Figure 2: S. marcescens colonisation and sepis.

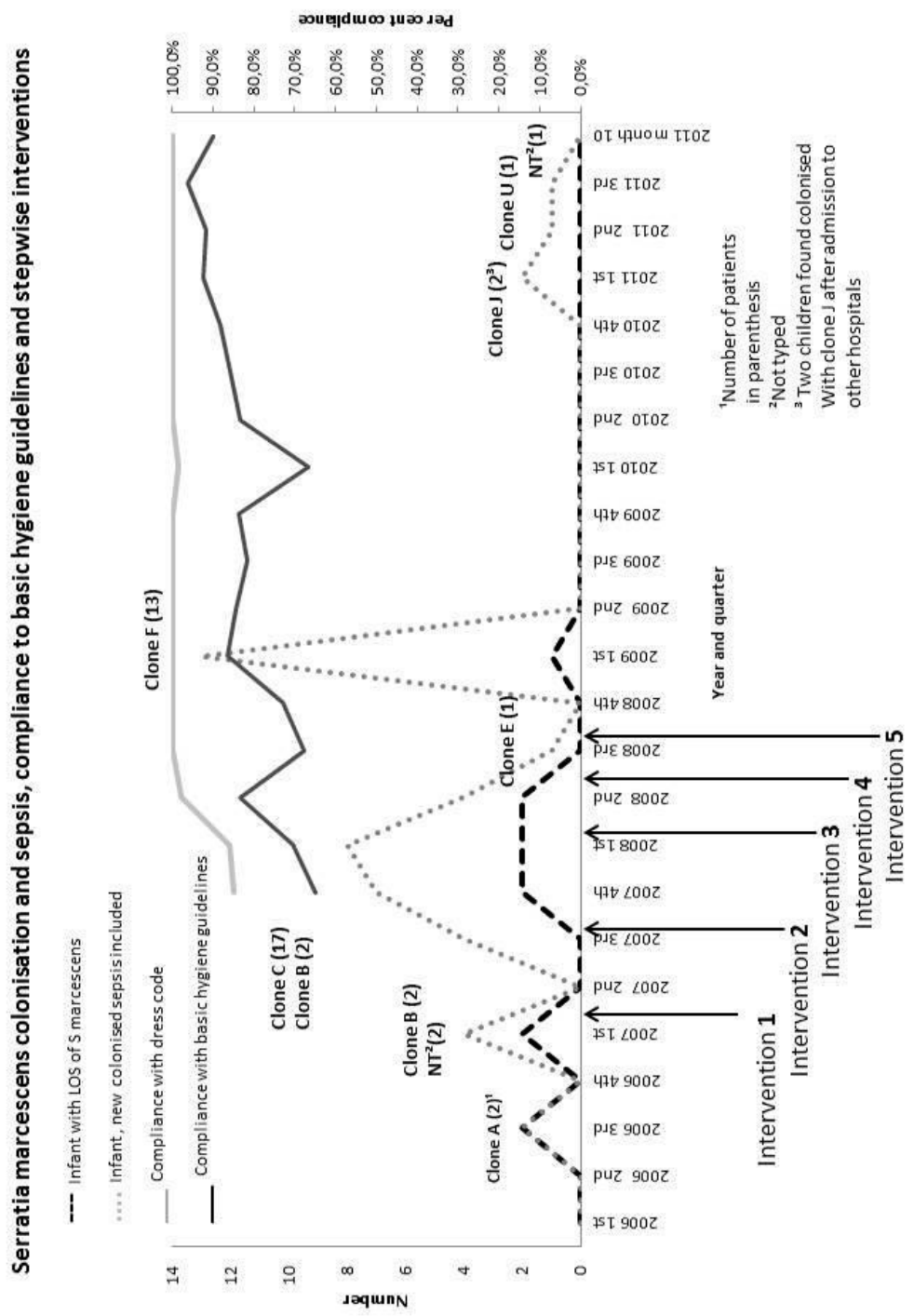

In the case-control study in Paper III, medical records of 190 patients with sepsis as discharge diagnosis were studied. Seventy-six patients fulfilled the sepsis criteria, 36 patients had EOS and 40 patients had LOS. In the LOS group there were 47 separate episodes of sepsis in 40 patients. Eleven patients had 12 separate episodes of LOS-ser. The records of one infant with S. marcescens 
septicaemia in August 2006 were not complete and this case was not included in the risk factor study, but is included in Figure 2.There were no S. marcescens sepsis cases in the EOS group. Fortyseven control cases were included.

In the comparison of the LOS-group with controls, the risk for LOS decreased significantly with every day of gestation age at birth and $\mathrm{kg}$ of birth weight with odds ratios 0.98 and 0.17 respectively. The risk for LOS also increased for each day with a central vein or umbilical catheter, and each day of ventilator treatment, with odds ratios 2.6 and 1.6 respectively.

In the comparison of LOS-ser with LOS-non-ser, there were no significant differences. In analysis with stepwise logistic regression, birth-weight was excluded because it was dependent on gestational age at birth. No other risk factors were found in this analysis.

\section{Paper IV}

In the study group with appendicitis the median age was 47 (19-82) years, in the diverticulitis group $62(39-84)$ years and in the control group $48(23-70)$, the median age in the diverticulitis group being significant higher. The difference in gender distribution was not significant. The patients in the appendicitis and diverticulitis groups had raised CRP ( 136(7-350) and 121(6-337)) and WCC (16.6(5.5-25.8) and (15.6(9.9-68.0)) respectively, previous antibiotic treatment (6 patients (15.0\%) and 3(16.7)) , days in hospital (5(2-10) and 6(2-19)), days of antibiotic treatment ( $12(2-23)$ and $14(4-$ 21)),perforation of the appendix and large intestine respectively( 7 patients (16.7\%) and 4(21.1)) with no significant differences. A significant difference was found in the rate of surgery 38 patients $(90.5$ $\%)$ in the appendicitis group and 4 patients (21.1\%) in the diverticulitis group.

All patients received antibiotic therapy with broad in-vitro effect on aerobic and anaerobic bacteria. Twenty-six patients in the appendicitis group and 10 patients in the diverticulitis group received intravenous carbapenem (meropenem, imipenem or ertapenem). Cefalosporin (cefotaxime or 
cefuroxime) in combination with metronidazole was chosen as antibiotic therapy in 16 appendicitis patients and nine diverticulitis patients.

Looking into the sequencing data of the faecal microbiota at genus level (figure 3); there were distinctive differences when comparing healthy controls to patients diagnosed with appendicitis. Healthy controls have a microbiota dominated by Bacteroides, Faecalibacterium, Ruminococceae and Prevotella while appendicitis patients show an intestinal flora with a higher abundance of Escherichia/Shigella and unclassified Enterobacteriaceae. The same pattern, however not quite as distinct could be seen for the diverticulitis patients.

Figure 3: Taxonomic composition by genus

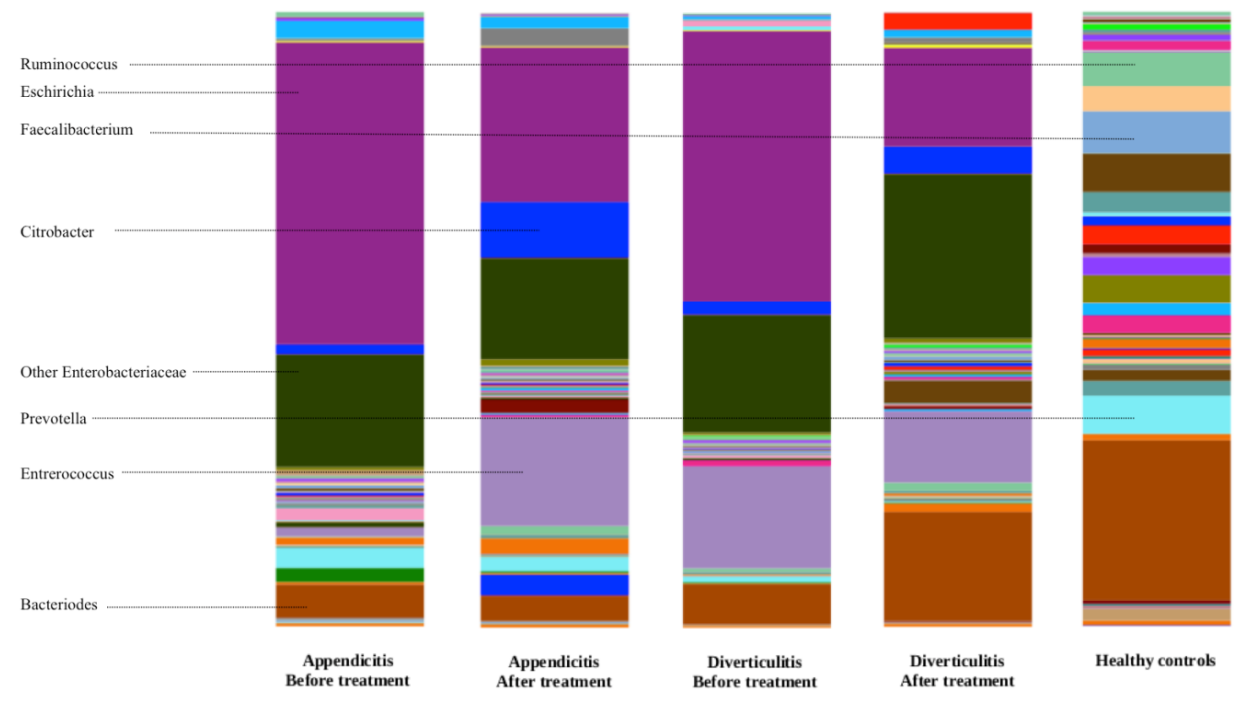

Before: Sample taken just before antibiotic treatment start, in a patient with appendicitis or diverticulitis.

After: Sample taken 2-14 days after end of antibiotic treatment

Looking at data on phyla level (figure 4) there was a distinct difference between the study populations and the control population, in which Proteobacteria and Bacteroidetes occurring to a 
greater extent in the study population, whereas Firmicutes and Actinobacteria are more abundant in the control population.

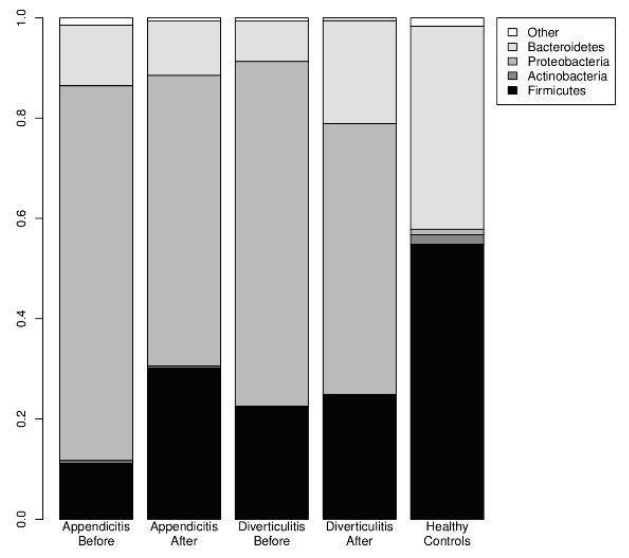

Figure 4: Taxonomic composition on phyla level

Before: Sample taken just before antibiotic treatment start, in a patient with appendicitis or diverticulitis.

After: Sample taken 2-14 days after end of antibiotic treatment

The diversity (figure 5) was significantly lower in the two study groups compared with healthy controls in samples before treatment. In the diverticulitis group the diversity increased significantly after antibiotic treatment and hospitalisation.

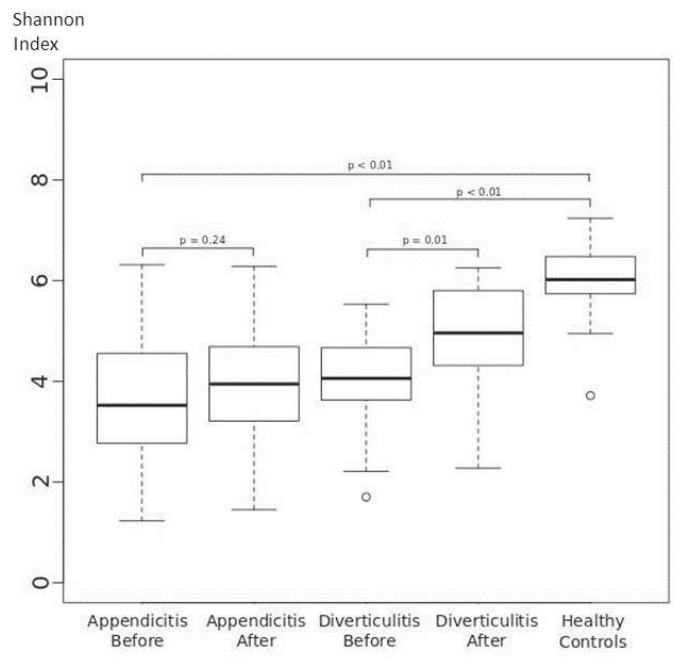

Figure 5: Diversity (Shannon Index) Before: sample taken just before start of antibiotic treatment start, in a patient with appendicitis or diverticulitis.

After: sample taken 2-14 days after end of antibiotic treatment.

Differences between groups are calculated using Wilcoxon's unpaired rank test. $p$-value $<0.01$ is considered 
In cultures from the microbiota there was a significant loss of $E$ coli and a significant gain of Citrobacter species in the appendicitis group. In the appendicitis group as well as in the diverticulitis group there were a significant gain of $E$ faecium and Yeasts.

The loss of E. coli and gain of Citrobacter species and enterococci between the standard cultivation methods was consistent with 16S rRNA sequence analyses in the appendicitis group. 


\section{Discussion}

In Paper I a multi-clonal outbreak of enterococcal sepsis on a general ICU was identified. The environment was soiled with enterococci and transmission between patients was identified in seven cases, and between patients and environment in two cases. The most severe manifestation of the infection was sepsis. After implementation of the intervention programme no further outbreak of enterococal sepsis occurred. We were not able to determine if any particular part of the intervention programme was more important or whether this was a result of the intervention programme at all. Enterococci are able to survive in the environment for up to three months (138) and studies have shown the importance of appropriate cleaning to eradicate enterococci from a ward $(139,140)$. It is reasonable to presume that thorough cleaning was important. The use of cefalosporins and antibiotics with anaerobic effect are known risk-factors for infection or colonisation with enterococci (141). Furthermore over-all mortality and severity of illness was unchanged. The reduction over all was probably due to decrease in occupancy since DDD per ICU patient was not changed. Reduction in antibiotic usage is generally beneficial for the bacterial ecology of the hospital and for ICU cost containment. Extraction of figures from hospital pharmacy-delivery data is not optional for assessing antibiotic consumption and appropriate usage. With the advent of computerised patient records, where notes on indication for therapy at the time of prescription are mandatory, details on indication for antibiotic treatment will become much more dependable. Increase in bed occupancy often leads to understaffing which could enhance MRSA transmission(142) due to a decrease in compliance to hygiene guidelines and a reduction in the capacity isolate patients or perform cohortcare. In this study, increased bed occupancy and suboptimal use of the rooms were probably predisposing factors for the outbreak. Adherence to basic hygiene guidelines is an important measure in the prevention of healthcare-associated infections (143). The present data also illustrate how difficult infection control can be when endemic infection rates are unknown because of poorly kept of infection-records. The importance of active surveillance through continuous registration infections seems obvious. The consequence of this is that it is difficult to draw definitive conclusions 
from our results. Basic hygiene routines, optimal antibiotic therapy, (with choice based on resistance pattern and given as soon as possible instead of the overuse of broad-spectrum antibiotics) and ability to isolate of infected patients should be standard in all ICUs.

In Paper II we found a shift in faecal floral pattern from E. coli to other Enterobacteriaceae, E. faecium and yeasts in samples from patients after treatment with antibiotics for acute intraabdominal infection in the clinical setting. Most studies on the effect of antibiotic treatment on the gut flora have been performed in healthy human volunteers (144). The fraction of decreased susceptibility to cefalosporins and piperacillin-tazobactam in Enterobacteriaceae increased after antibiotic treatment. The loss of $E$. coli and gain of other Enterobacteriaceae, and the shift to $E$. faecium was mainly a shift to species with greater intrinsic antibiotic resistance. This indicates that the emergence of antibiotic resistance is not due to mutations but selection of more resistant species. In multicentre studies similar to ours, a substantial increase in bowel colonisation with resistant Enterobacteriaceae in patients treated with piperacillin-tazobactam or ceftriaxone in combination with metronidazole was seen, which is in agreement with our findings (145).

Most of the antibiotics observed in this study are mainly eliminated via the urinary tract, the amount found in faeces is often low (approximately 1-5\%) $(79,83,86,92,93,146)$, but nevertheless the aerobic composition of the faecal flora was affected. We could not ascertain what effects the antibiotic regimens had on the faecal flora because this study did not have the power for that.

Some studies indicate that harbouring of antibiotic-resistant Enterobacteriaceae in the faeces increases the risk for being infected by that subtype after hospital admission $(147,148)$. Thus the shift towards more antibiotic-resistant species must be taken into consideration when designing treatment regiments for secondary intra-abdominal infections.

In Paper III, we identified different clones with each outbreak, except for overlapping of clone B and C during fourth quarter of 2007, where an infant from a referring hospital already was colonised with clone B at admission and caused a spread. A decrease in LOS-ser, and no further major outbreak of 
S. marcescens colonisation after early 2009 was observed after implementing the five -stage intervention programme. We were not able to identify any specific effects of individual intervention measures. The spread of S. marcescens decreased, however, when compliance with hygiene rules remained at a steady high level after the $4^{\text {th }}$ quarter of 2008 , with one exception in early 2010 . This may reflect a delay in the adoption of new routines, and we believe that our intervention programme had a positive effect on the occurrence of S. marcescens. Observation of compliance with basic hygiene guidelines helps maintain awareness of the importance of all hygiene and cleaning routines(149). The decrease in the S. marcescens sepsis rate after change of antibiotic policy illustrates the importance of modifying existing antibiotic regimens according to local culture findings. It is also important to discuss measures with the microbiological laboratory when there are recurrent breakthroughs of sepsis, during empiric antibiotic treatment. In our case we were obliged to MIC-tests from disc-diffusion testing in order to reveal the most suitable aminoglycoside, taking variations in in vivo concentrations into consideration. The transmission of S. marcescens via a pacifier illustrates the importance of adequate cleaning and storing routines, and the risk of sharing devices. We were not able to identify the source of $S$. marcescens despite a large number of cultures from the environment. Even though S. marcescens was not found on the hands of the nursing staff, handling is an important way of transmission and hand hygiene is crucial in preventing contact transmission(13). The importance of revising hygiene and cleaning routines, as well as antibiotic strategies has been described by Voelz (150). During an outbreak situation it is important to ensure that hygiene guidelines are properly followed, adequate and updated if necessary. The spread of bacteria between patients should be considered a failure in hygiene routines and must lead to adequate control measures even if the source of the outbreak has not been identified.

We also found that central venous or umbilical catheter, ventilator care and low gestational age at birth are independent risk factors for LOS, which is in accordance with other studies. $(151,152)$. We 
did not see any significant differences between non-Serratia LOS and LOS with S. marcescens. This could be due to the small numbers in each group. Looking back over the six year observation period, we believe that allocation of infants born prior to 28 weeks of gestation, to a special management cohort facilitates the awareness of their fragility and underlines the importance of compliance to hygiene routines. We believe that prophylactic cohort-care also protected these children from being colonised and infected with S. marcescens.

In Paper IV, the patients arriving at the emergency department with acute appendicitis or diverticulitis already had significantly disturbed faecal microbiota prior to antibiotic treatment and hospitalisation. At genus level, the healthy controls had a flora dominated by Bacteroides, Faecalibacterium, Ruminococceae and Prevotella, while appendicitis patients showed an intestinal flora with a higher Escherichia/Shigella and unclassified Enterobacteriaceae content. The absence of F prausnitzii is associated with several inflammatory diseases of the bowel (153). Chassaing et al. suggested that the ratio of $F$. prausnitzii/ E. coli can be used to evaluate the microbiota disturbance level (dysbiosis) in patients with inflammatory bowel disease, and identify those at high risk for recurrent relapses of Crohn's disease(154). This could indicate that a change in the gut microbiota is part of the pathogenesis of both appendicitis and diverticulitis. Microbial diversity increases after treatment with broad spectrum antibiotics and hospitalisation. Conventional aerobic cultivations show a shift towards E. faecium and Yeasts indicating disturbed microbiota. The shift from E. coli towards other Enterobacteriaceae in the appendicitis group could be an expression of displacement of one species by another with more intrinsic antibiotic resistance as shown in Paper II. Freezing of the samples could have influenced faecal composition with a reduction in the proportion of Bacteroidetes (155). This should not have affected the dynamics between the two sampling occasions in the study population. 


\section{Conclusion}

- A multi-clonal outbreak of enterococcal sepsis on a general ICU was identified. The environment was soiled with enterococci and transmission between patients and between patients and environment had occurred. The most severe manifestation of the infection was sepsis.

- After improved hygiene routines including reorganisation of rooms and thorough cleaning of the GICU together with revision of antibiotic regimens reduced the incidence of septicaemia with Enterococcus spp and prevented clustering of enterococcal infections, was observed.

- Antibiotic treatment and hospital care, of patients treated for acute intra-abdominal infections, leads to a shift in the aerobic faecal flora from antibiotic-susceptible Enterobacteriaceae towards E. faecium, yeasts and more antibiotic-resistant species of Enterobacteriaceae.

- Epidemiological typing showed that recurrent outbreaks of Serratia maecescens was caused by different clones each outbreak, but within one outbreak the major part was caused by a single clone, demonstrating spread between neonates at a NICU.

- Multiple hygiene interventions and revised antibiotic regimens eventually obviate recurrent outbreaks of Serratia marcescens on the NICU. Spread of Serratia marcescens was not reduced until the observed compliance with basic hygiene guidelines remained stable above $80 \%$.

- Low gestational age at birth, weight at sepsis onset, ventilator treatment and central venous or umbilical catheters are independent risk factors for late onset-sepsis, among patients on the NICU.

- In patients with acute appendicitis or diverticulitis the faecal microbiota is already disturbed with a higher content of Enterobacteriaceae spp and less Bacteroides, Faecalibacterium, Ruminococcus and Prevotella than the control population. In the group with acute 
appendicitis there was no significant difference in the diversity before and after antibiotic treatment and hospitalisation. In the diverticulitis group the faecal diversity increased significantly and approached the healthy controls after antibiotic-treatment and hospitalisation. 


\section{Acknowledgement}

I would like to express my sincere thanks to all people sharing their experience, knowledge and time with me in the work with this thesis with special greeting to:

Håkan Hanberger my supervisor: for valuable advices and input on my writing, with illuminative questions and your devotion to the subject of infection diseases and antibiotic treatment.

Barbro Isaksson, co-supervisor and former supervisor: introducing me to infection control and research and for sharing your great experience, also for creating time to research in my daily work.

Jon Jonasson, co-supervisor: for sharing your great skill on molecular biology and giving input on writing.

Lars G Buhrman: former co-supervisor, for taking part in the planning of my PhD-thesis.

Elisabeth Olhager, co-writer: for sharing your great knowledge in the field of Neonatology and the collaboration in the joint venture of limiting the outbreak of $S$ marcescens.

Lars Engstrand, co-writer: for sharing knowledge of molecular methods and microbiota.

Maud Nilsson and Anita Johansson: for all laboratory work on mapping the aerobic faecal flora with culture methods.

Abbas Chabok, co-writer: for your work with the collection of clinical samples from surgical patients.

Olle Eriksson and Kalle Wallin: for statistical advices and patience with my questions.

Hans-Jürg Monstein, co-writer and teacher in molecular biology.

Erik Kihlström, professor in clinical microbiology: for giving me time to research.

Urban Forssum, professor emeritus in clinical microbiology: for introducing clinical microbiology and molecular biology to me.

All other co-writers, Lennart Nilsson, Sören Berg, Hugo Wefer, Annika Fahlén, Lars Agréus, Anna Nixon Andreasson and Daniel Lundin.

Peter Cox: for your patients amending my English writing.

My present and former research co-workers on the Hygiene department: Laila Kyllinger, for all environmental cultures and advices; Karin Strand and Anita Antonsson-Schütz, for taking environmental cultures and the support in investigation of the NICU and ICU outbreaks; Elisabeth Palmquist in laboratory work with enterococci; Maria Lindquist, for laboratory work with $S$ marcescens.

My family: Anders, my beloved husband and greatest supporter. My daughter Karin: for your skills in analysing situations and persons. My son Erik: you make me see the world from a different angel and give me spiritual input. My mother Rigmor and father Bertil, for always believe in me and bringing me up in a home where critical thinking and education was important. My brother Olof for all good times we shared. 


\section{References}

1. who.int [Internet]. Geneva World Health Organization; [cited 2013 May 28]; Available from: http://www.who.int/gpsc/country work/burden hcai/en/.

2. Pratt RJ, Pellowe C, Loveday HP, Robinson N, Smith GW, Barrett S, et al. The epic project: developing national evidence-based guidelines for preventing healthcare associated infections. Phase I: Guidelines for preventing hospital-acquired infections. Department of Health (England). J Hosp Infect. 2001;47 Suppl:S3-82. Epub 2001/02/13.

3. Kaoutar B, Joly C, L'Hériteau F, Barbut F, Robert J, Denis M, et al. Nosocomial infections and hospital mortality: a multicentre epidemiological study. Journal of Hospital Infection. 2004;58:268-75.

4. Stoll BJ, Hansen N, Fanaroff AA, Wright LL, Carlo WA, Ehrenkranz RA, et al. Late-onset sepsis in very low birth weight neonates: the experience of the NICHD Neonatal Research Network. Pediatrics. 2002;110:285-91. Epub 2002/08/08.

5. Norman M, Blennow M, Vineta F, Hellström A, Hellström-Westas L, Holmström G, et al. Incidence of and Risk Factors for Neonatal Morbidity After Active Perinatal Care: Extremely Preterm Infants Study in Sweden (Express): 150. Pediatric Research. 2010:79.

6. Borghesi A, Stronati M. Strategies for the prevention of hospital-acquired infections in the neonatal intensive care unit. J Hosp Infect. 2008;68:293-300. Epub 2008/03/11.

7. Vergnano S, Sharland M, Kazembe P, Mwansambo C, Heath PT. Neonatal sepsis: an international perspective. Archives of Disease in Childhood-Fetal and Neonatal Edition. 2005;90:220-4.

8. Best M, Neuhauser D. Ignaz Semmelweis and the birth of infection control. Qual Saf Health Care. 2004;13:233-4. Epub 2004/06/04.

9. Schwartz M. The life and works of Louis Pasteur. Journal of Applied Microbiology. 2001;91:597-601.

10. Grimes DJ. Koch's Postulates-Then and Now. MicrobeAmerican Society for Microbiology. 2006;1:223.

11. Siegel JD, Rhinehart E, Jackson M, Chiarello L. 2007 Guideline for Isolation Precautions: Preventing Transmission of Infectious Agents in Health Care Settings. Am J Infect Control. 2007;35:S65-S164.

12. In: Skerman VBD, McGowan V, Sneath PHA, editors. Approved Lists of Bacterial Names (Amended). Washington DC: ASM Press; 1989.

13. Pittet D, Allegranzi B, Sax H, Dharan S, Pessoa-Silva CL, Donaldson L, et al. Evidence-based model for hand transmission during patient care and the role of improved practices. Lancet Infectious Diseases. 2006;6:641-52.

14. Noble WC. Dispersal of skin microorganisms. Br J Dermatol. 1975;93:477-85. Epub 1975/10/01.

15. Donskey CJ. The role of the intestinal tract as a reservoir and source for transmission of nosocomial pathogens. Clin Infect Dis. 2004;39:219-26.

16. Goodman ER, Platt R, Bass R, Onderdonk AB, Yokoe DS, Huang SS. Impact of an environmental cleaning intervention on the presence of methicillin-resistant Staphylococcus aureus and vancomycin-resistant enterococci on surfaces in intensive care unit rooms. Infect Control Hosp Epidemiol. 2008;29:593-9. Epub 2008/07/16.

17. Hayden MK, Blom DW, Lyle EA, Moore CG, Weinstein RA. Risk of hand or glove contamination after contact with patients colonized with vancomycin-resistant enterococcus or the colonized patients' environment. Infect Control Hosp Epidemiol. 2008;29:149-54. Epub 2008/01/09.

18. Getchell-White SI, Donowitz LG, Groschel DH. The inanimate environment of an intensive care unit as a potential source of nosocomial bacteria: evidence for long survival of 
Acinetobacter calcoaceticus. Infect Control Hosp Epidemiol. 1989;10:402-7. Epub 1989/09/01.

19. Weber DJ, Rutala WA, Miller MB, Huslage K, Sickbert-Bennett E. Role of hospital surfaces in the transmission of emerging health care-associated pathogens: norovirus, Clostridium difficile, and Acinetobacter species. Am J Infect Control. 2010;38:S25-33. Epub 2010/07/01.

20. Boyce JM. Environmental contamination makes an important contribution to hospital infection. J Hosp Infect. 2007;65 Suppl 2:50-4. Epub 2007/08/19.

21. Casewell M, Phillips I. Hands as route of transmission for Klebsiella species. Br Med J. 1977;2:1315-7. Epub 1977/11/19.

22. Ehrenkranz NJ, Alfonso BC. Failure of bland soap handwash to prevent hand transfer of patient bacteria to urethral catheters. Infect Control Hosp Epidemiol. 1991;12:654-62. Epub 1991/11/01.

23. Waters V, Larson E, Wu F, San Gabriel P, Haas J, Cimiotti J, et al. Molecular epidemiology of gram-negative bacilli from infected neonates and health care workers' hands in neonatal intensive care units. Clin Infect Dis. 2004;38:1682-7. Epub 2004/07/01.

24. Pittet D, Dharan S, Touveneau S, Sauvan V, Perneger TV. Bacterial contamination of the hands of hospital staff during routine patient care. Arch Intern Med. 1999;159:821-6. Epub 1999/04/29.

25. Pessoa-Silva CL, Dharan S, Hugonnet S, Touveneau S, Posfay-Barbe K, Pfister R, et al. Dynamics of bacterial hand contamination during routine neonatal care. Infect Control Hosp Epidemiol. 2004;25:192-7. Epub 2004/04/06.

26. Noskin GA, Stosor V, Cooper I, Peterson LR. Recovery of vancomycin-resistant enterococci on fingertips and environmental surfaces. Infect Control Hosp Epidemiol. 1995;16:577-81. Epub 1995/10/01.

27. Fryklund B, Tullus K, Burman LG. Survival on skin and surfaces of epidemic and non-epidemic strains of enterobacteria from neonatal special care units. J Hosp Infect. 1995;29:201-8. Epub 1995/03/01.

28. Zachary KC. Contamination of gowns, gloves, and stethoscopes with vancomycin-resistant. Infect Control Hosp Epidemiol 2001;22:560.

29. McNeil SA, Foster CL, Hedderwick SA, Kauffman CA. Effect of hand cleansing with antimicrobial soap or alcohol-based gel on microbial colonization of artificial fingernails worn by health care workers. Clin Infect Dis. 2001;32:367-72. Epub 2001/02/15.

30. Gupta A, Della-Latta P, Todd B, San Gabriel P, Haas J, Wu F, et al. Outbreak of extendedspectrum beta-lactamase-producing Klebsiella pneumoniae in a neonatal intensive care unit linked to artificial nails. Infect Control Hosp Epidemiol. 2004;25:210-5. Epub 2004/04/06.

31. Trick WE, Vernon MO, Hayes RA, Nathan C, Rice TW, Peterson BJ, et al. Impact of ring wearing on hand contamination and comparison of hand hygiene agents in a hospital. Clin Infect Dis. 2003;36:1383-90. Epub 2003/05/27.

32. Salisbury DM, Hutfilz P, Treen LM, Bollin GE, Gautam S. The effect of rings on microbial load of health care workers' hands. Am J Infect Control. 1997;25:24-7. Epub 1997/02/01.

33. Fagernes $\mathrm{M}$, Lingaas $\mathrm{E}$. Impact of finger rings on transmission of bacteria during hand contact. Infect Control Hosp Epidemiol. 2009;30:427-32. Epub 2009/04/07.

34. Dancer S. Importance of the environment in meticillin-resistant Staphylococcus aureus acquisition: the case for hospital cleaning. The Lancet infectious diseases. 2008;8:101-13.

35. Huang SS, Datta R, Platt R. Risk of acquiring antibiotic-resistant bacteria from prior room occupants. Arch Intern Med. 2006;166:1945-51. Epub 2006/10/13.

36. Drees MM. Prior Environmental Contamination Increases the Risk of Acquisition of Vancomycin-Resistant Enterococci. Clinical infectious diseases. 2008;46:678-85.

37. Perry C. Bacterial contamination of uniforms. J Hosp Infect. 2001;48:238-41.

38. Wong D. Microbial flora on doctors' white coats. BMJ. 1991;303:1602-4.

39. Dixon M. Neck ties as vectors for nosocomial infection. Intensive care medicine. 2000;26:250. 
40. van der Reijden CMJEA. Survival of bacteria on uniforms in relation to risk management in dental clinics. J Hosp Infect. 2009;73:283-5.

41. de Vries JJC, Baas WH, van der Ploeg K, Heesink A, Degener JE, Arends JP. Outbreak of Serratia marcescens colonization and infection traced to a Healthcare worker with long-term carriage on the hands. Infection Control and Hospital Epidemiology. 2006;27:1153-8.

42. Heinrich N, Mueller A, Bartmann P, Simon A, Bierbaum G, Engelhart S. Successful management of an MRSA outbreak in a neonatal intensive care unit. Eur J Clin Microbiol Infect Dis. 2011;30:909-13. Epub 2011/02/08.

43. Gerber SI, Jones RC, Scott MV, Price JS, Dworkin MS, Filippell MB, et al. Management of outbreaks of methicillin-resistant Staphylococcus aureus infection in the neonatal intensive care unit: a consensus statement. Infect Control Hosp Epidemiol. 2006;27:139-45. Epub 2006/02/09.

44. Harbarth S, Sax H, Gastmeier P. The preventable proportion of nosocomial infections: an overview of published reports. Journal of Hospital Infection. 2003;54:258-66.

45. skl.se [Internet]. Stockholm: Swedish Association of Local Authorities and Regions; 2011-2013 [updated 2013 February 18; cited 2013 May 2]; Available from:

http://www.skl.se/vi arbetar med/halsaochvard/patientsakerhet/riskomraden.

46. van Belkum A, Tassios PT, Dijkshoorn L, Haeggman S, Cookson B, Fry NK, et al. Guidelines for the validation and application of typing methods for use in bacterial epidemiology. Clin Microbiol Infect. 2007;13 Suppl 3:1-46. Epub 2007/11/06.

47. Reingold AL. Outbreak investigations--a perspective. Emerg Infect Dis. 1998;4:21-7. Epub 1998/03/21.

48. Haill C, Fletcher S, Archer R, Jones G, Jayarajah M, Frame J, et al. Prolonged outbreak of meticillin-resistant Staphylococcus aureus in a cardiac surgery unit linked to a single colonized healthcare worker. Journal of Hospital Infection. 2013.

49. Ali H, Nash J, Kearns A, Pichon B, Vasu V, Nixon Z, et al. Outbreak of a South West Pacific clone Panton-Valentine leucocidin-positive meticillin-resistant Staphylococcus aureus infection in a UK neonatal intensive care unit. Journal of Hospital Infection. 2012;80:293-8.

50. Rettedal S, Löhr IH, Natås O, Sundsfjord A, Øymar K. Risk factors for acquisition of CTX-M-15 extended-spectrum beta-lactamase-producing Klebsiella pneumoniae during an outbreak in a neonatal intensive care unit in Norway. Scand J Infect Dis. 2013;45:54-8.

51. Tham J, Walder M, Melander E, Odenholt I. Duration of colonization with extended-spectrum beta-lactamase-producing Escherichia coli in patients with travellers' diarrhoea. Scand J Infect Dis. 2012;44:573-7.

52. R L, A D, A H, B I, K M, I R-Ö, editors. Att förebygga vårdrelaterade infektioner-ett kunskapsunderlag. 2:nd ed. Stockholm2006.

53. Murray PR, Baron EJ, Jorgensen JH, Pfaller MA, Landry ML, editors. Manual of Clinical Microbiology. 9 ed. Washington DC: American Society of Microbiology; 2007.

54. Mandell GL, Bennett JE, Dolin R, editors. Mandell, Douglas, and Bennett's Principles and Practice of Infectious DIseases. . 7 th ed. Pensylvania US: Churchill Livingstone Elsevier; 2010.

55. Edelstein M, Kortsalioudaki C, Johnson A, Hope R, Chickowska A, Sharland M. G88 Monitoring of Healthcare-Associated Infection Outbreaks in Neonatal Units in England. Archives of Disease in Childhood. 2013;98:A44-A.

56. Anthony M, Bedford-Russell A, Cooper T, Fry C, Heath PT, Kennea N, et al. Managing and preventing outbreaks of Gram-negative infections in UK neonatal units. Archives of Disease in Childhood-Fetal and Neonatal Edition. 2013.

57. Hejazi A, Aucken HM, Falkiner FR. Epidemiology and susceptibility of serratia marcescens in a large general hospital over an 8-year period. J Hosp Infect. 2000;45:42-6. Epub 2000/06/02.

58. Hejazi A, Falkiner F. Serratia marcescens. Journal of Medical Microbiology. 1997;46:903-12.

59. Bourigault C, Corvec $S$, Bretonnière $C$, Guillouzouic $A$, Crémet L, Marraillac J, et al. Investigation and management of multidrug-resistant $<\mathrm{i}>$ Acinetobacter baumannii</i> 
spread in a French medical intensive care unit: One outbreak may hide another. Am J Infect Control. 2012.

60. La Forgia C, Franke J, Hacek DM, Thomson RB, Robicsek A, Peterson LR. Management of a multidrug-resistant $<\mathrm{i}>$ Acinetobacter baumannii $</ \mathrm{i}>$ outbreak in an intensive care unit using novel environmental disinfection: A 38-month report. Am J Infect Control. 2010;38:259-63.

61. Cornaglia G, Mazzariol A, Lauretti L, Rossolini GM, Fontana R. Hospital outbreak of carbapenem-resistant Pseudomonas aeruginosa producing VIM-1, a novel transferable metallo- $\beta$-lactamase. Clinical infectious diseases. 2000;31:1119-25.

62. Widmer A, Wenzel R, Trilla A, Bale M, Jones R, Doebbeling B. Outbreak of Pseudomonas aeruginosa infections in a surgical intensive care unit: probable transmission via hands of a health care worker. Clinical infectious diseases. 1993;16:372-6.

63. Landman D, Quale JM, Mayorga D, Adedeji A, Vangala K, Ravishankar J, et al. Citywide clonal outbreak of multiresistant Acinetobacter baumannii and Pseudomonas aeruginosa in Brooklyn, NY: the preantibiotic era has returned. Arch Intern Med. 2002;162:1515.

64. Martone WJ. Spread of vancomycin-resistant enterococci: why did it happen in the United States? Infect Control Hosp Epidemiol. 1998;19:539-45. Epub 1998/10/03.

65. Marinella MA. The stethoscope and potential nosocomial infection. Infect Control Hosp Epidemiol. 1998;19:477-8. Epub 1998/08/14.

66. Livornese LL, Jr., Dias S, Samel C, Romanowski B, Taylor S, May P, et al. Hospital-acquired infection with vancomycin-resistant Enterococcus faecium transmitted by electronic thermometers. Ann Intern Med. 1992;117:112-6. Epub 1992/07/25.

67. Gould FK, Freeman R. Nosocomial infection with microsphere beds. Lancet. 1993;342:241-2. Epub 1993/07/24.

68. Orr KE, Gould FK, Perry JD, Ford M, Morgan S, Sisson PR, et al. Therapeutic beds: the Trojan horses of the 1990s? Lancet. 1994;344:65-6. Epub 1994/07/02.

69. Gordon RJ, Lowy FD. Pathogenesis of methicillin-resistant Staphylococcus aureus infection. Clin Infect Dis. 2008;46 Suppl 5:S350-9. Epub 2008/05/28.

70. Lindborg K. Antibiotikaflödet i Sverige: Kvalitetsgranskning av försäljningsstatistik 2002: Mälardalen University; 2008.

71. Fleming A. Classics in infectious diseases: on the antibacterial action of cultures of a penicillium, with special reference to their use in the isolation of $B$. influenzae by Alexander Fleming, Reprinted from the British Journal of Experimental Pathology 10:226-236, 1929. Rev Infect Dis. 1980;2:129-39. Epub 1980/01/01.

72. reactgroup.org [Internet] ReAct - Action on Antibiotic Resistance; 2011 [updated 2013 August 20; cited 2011 April 7]; Available from: http://www.reactgroup.org/what-wedo/react-world-health-day.html.

73. Levy SB. Microbial resistance to antibiotics. An evolving and persistent problem. Lancet. 1982;2:83-8. Epub 1982/07/10.

74. Holmberg SD, Solomon SL, Blake PA. Health and economic impacts of antimicrobial resistance. Rev Infect Dis. 1987;9:1065-78. Epub 1987/11/01.

75. Alekshun SBB. Molecular mechanisms of antibacterial multidrug resistance. Cell. 2007;128:1037-50.

76. Paterson DL, Bonomo RA. Extended-spectrum beta-lactamases: a clinical update. Clinical Microbiology Reviews. 2005;18:657-+.

77. Kumarasamy KK, Toleman MA, Walsh TR, Bagaria J, Butt F, Balakrishnan R, et al. Emergence of a new antibiotic resistance mechanism in India, Pakistan, and the UK: a molecular, biological, and epidemiological study. The Lancet infectious diseases. 2010;10:597-602.

78. Grayson ML, Crowe SM, McCarthy JS, Mills J, Mouton JW, Norrby SR, et al., editors. Kucers' The Use of Antibiotics. 6th ed. London, UK: Hodder Arnold Hodder Education Hatchet UK; 2010.

79. Sorgel F, Kinzig M. The chemistry, pharmacokinetics and tissue distribution of pipercillin tazobactame. J Antimicrob Chemother. 1993;31:39-60. 
80. smittskyddsinstitutet.se [Internet]. Stockholm: The Swedish Institute for Communicable Disease Control [updated 2012 August 21; cited 2013 August 20]; Available from: http://smittskyddsinstitutet.se/raf/antibiotika/.

81. Jones RN, Baquero F, Privitera G, Inoue M, Wiedemann B. Inducible $\beta$-lactamase-mediated resistance to third-generation cephalosporins. Clinical Microbiology and Infection. 1997;3:s7s20.

82. Jacoby GA. AmpC beta-lactamases. Clin Microbiol Rev. 2009;22:161-82, Table of Contents. Epub 2009/01/13.

83. Severn M, Powis SJA. Biliary-excretion and tissue-levels of cefuroxime-study in 11 patients undergoing cholecystectomy. J Antimicrob Chemother. 1979;5:183-8.

84. Soussy CJ, Deforges LP, Le Van Thoi J, Feghali W, Duval JR. Cefotaxime concentration in the bile and wall of the gallbladder. Journal of Antimicrobial Chemotherapy. 1980;6:125.

85. lakemedelsverket.se [Internet]. Uppsala: The Medical Products Agency, Swedish national authority.; 2013 [cited 2013 august 20]; Available from:

http://www.lakemedelsverket.se/Sok-pa-webbplatsen/?q=ceftazidim+sandoz.

86. Harrison MP, Haworth SJ, Moss SR, Wilkinson DM, Featherstone A. The disposition and metabolic-fate of C-14 meropenem in man. Xenobiotica. 1993;23:1311-23.

87. Wong BK, Xu X, Yu S, Lin JH, Singh R, Sahly Y, et al. Comparative disposition of [C14] 2004;34:379-89.

88. Drlica K, Hiasa H, Kerns R, Malik M, Mustaev A, Zhao X. Quinolones: action and resistance updated. Curr Top Med Chem. 2009;9:981-98. Epub 2009/09/15.

89. Lode H, Wiley R, Hoffken G, Wagner J, Borner K. Prospective randomized controlled study of ciprofloxacin versus imipenem-cilastatin in severe clinical infections. Antimicrob Agents Chemother. 1987;31:1491-6. Epub 1987/10/01.

90. Drusano GL, Johnson DE, Rosen M, Standiford HC. Pharmacodynamics of a fluoroquinolone antimicrobial agent in a neutropenic rat model of Pseudomonas sepsis. Antimicrob Agents Chemother. 1993;37:483-90. Epub 1993/03/01.

91. Hanberger H, Edlund C, Furebring M, C GG, Melhus A, Nilsson LE, et al. Rational use of aminoglycosides--review and recommendations by the Swedish Reference Group for Antibiotics (SRGA). Scand J Infect Dis. 2013;45:161-75. Epub 2012/12/29.

92. Mendelson J, Portnoy J, Sigman H. Pharmacology of gentamicin in the biliary tract of humans. Antimicrob Agents Chemother. 1973;4:538.

93. Rieder J. Excretion of sulfamethoxazole and trimethoprim into human bile. J Infect Dis. 1973;128:Suppl: 574 p.

94. Schwartz DE, Jeunet F. Comparative pharmacokinetic studies of ornidazole and metronidazole in man. Chemotherapy. 1976;22:19-29.

95. Dancer SJ. How do we assess hospital cleaning? A proposal for microbiological standards for surface hygiene in hospitals. J Hosp Infect. 2004;56:10-5. Epub 2004/01/07.

96. Weinstein RA. Epidemiology and control of nosocomial infections in adult intensive care units. Am J Med. 1991;91:179S-84S. Epub 1991/09/16.

97. Ley RE, Peterson DA, Gordon JI. Ecological and evolutionary forces shaping microbial diversity in the human intestine. Cell. 2006;124:837-48. Epub 2006/02/25.

98. Gerritsen J, Smidt H, Rijkers GT, de Vos WM. Intestinal microbiota in human health and disease: the impact of probiotics. Genes Nutr. 2011;6:209-40. Epub 2011/05/28.

99. Backhed F, Ley RE, Sonnenburg JL, Peterson DA, Gordon JI. Host-bacterial mutualism in the human intestine. Science. 2005;307:1915-20. Epub 2005/03/26.

100. Guarner F, Malagelada J-R. Gut flora in health and disease. Lancet. 2003;361:512-9.

101. Khan MT, Duncan SH, Stams AJ, van Dijl JM, Flint HJ, Harmsen HJ. The gut anaerobe Faecalibacterium prausnitzii uses an extracellular electron shuttle to grow at oxic-anoxic interphases. ISME J. 2012;6:1578-85. Epub 2012/02/24. 
102. Sekirov I, Russell SL, Antunes LC, Finlay BB. Gut microbiota in health and disease. Physiol Rev. 2010;90:859-904. Epub 2010/07/29.

103. Zoetendal EG, Akkermans ADL, Akkermans-van Vliet WM, de Visser JAGM, de Vos WM. The host genotype affects the bacterial community in the human gastronintestinal tract. Microbial Ecology in Health and Disease. 2001;13:129-34.

104. Wilson M. Bacteriology of humans: an ecological perspective: Wiley-Blackwell; 2009.

105. Dethlefsen L, McFall-Ngai M, Relman DA. An ecological and evolutionary perspective on human-microbe mutualism and disease. Nature. 2007;449:811-8. Epub 2007/10/19.

106. Vandamme P, Pot B, Gillis M, de Vos P, Kersters K, Swings J. Polyphasic taxonomy, a consensus approach to bacterial systematics. Microbiol Rev. 1996;60:407-38. Epub 1996/06/01.

107. Bergey DH, Whitman WB, Krieg NR, Staley JT. Bergey's Manual of Systematic Bacteriology: The Bacteroidetes, Spirochaetes, Tenericutes (mollicutes), Acidobacteria, Fibrobacteres, Fusobacteria, Dictyoglomi, Gemmatimonadetes, Lentisphaerae, Verrucomicrobia, Chlamydiae, and Planctomycetes: Springer; 2008.

108. Yang S, Rothman RE. PCR-based diagnostics for infectious diseases: uses, limitations, and future applications in acute-care settings. Lancet Infect Dis. 2004;4:337-48. Epub 2004/06/03.

109. Clarridge JE, 3rd. Impact of $16 \mathrm{~S}$ rRNA gene sequence analysis for identification of bacteria on clinical microbiology and infectious diseases. Clin Microbiol Rev. 2004;17:840-62, table of contents. Epub 2004/10/19.

110. Ronaghi M. Pyrosequencing sheds light on DNA sequencing. Genome research. 2001;11:3-11.

111. Benson DA, Cavanaugh M, Clark K, Karsch-Mizrachi I, Lipman DJ, Ostell J, et al. GenBank. Nucleic Acids Res. 2013;41:D36-42. Epub 2012/11/30.

112. Haas BJ, Gevers D, Earl AM, Feldgarden M, Ward DV, Giannoukos G, et al. Chimeric 16S rRNA sequence formation and detection in Sanger and 454-pyrosequenced PCR amplicons. Genome research. 2011;21:494-504.

113. Maidak BL, Cole JR, Lilburn TG, Parker CT, Jr., Saxman PR, Farris RJ, et al. The RDP-II (Ribosomal Database Project). Nucleic Acids Res. 2001;29:173-4. Epub 2000/12/23.

114. Altschul SF, Gish W, Miller W, Myers EW, Lipman DJ. Basic local alignment search tool. J Mol Biol. 1990;215:403-10. Epub 1990/10/05.

115. Oehmen CS, Baxter DJ. ScalaBLAST 2.0: rapid and robust BLAST calculations on multiprocessor systems. Bioinformatics. 2013;29:797-8. Epub 2013/01/31.

116. Lozupone C, Knight R. UniFrac: a new phylogenetic method for comparing microbial communities. Appl Environ Microbiol. 2005;71:8228-35.

117. Lozupone C, Lladser ME, Knights D, Stombaugh J, Knight R. UniFrac: an effective distance metric for microbial community comparison. ISME J. 2011;5:169-72. Epub 2010/09/10.

118. Liu Z, Lozupone C, Hamady M, Bushman FD, Knight R. Short pyrosequencing reads suffice for accurate microbial community analysis. Nucleic Acids Res. 2007;35:e120. Epub 2007/09/21.

119. Tenover FC, Arbeit RD, Goering RV, Mickelsen PA, Murray BE, Persing DH, et al. Interpreting Chromosomal DNA Restricition Patterns Produced by Pulsed-Field Gel-Eloctrophoresis Criteria for Bacterial Strain Typing. J Clin Microbiol 1995;33:2233-9.

120. Knaus WA, Draper EA, Wagner DP, Zimmerman JE. APACHE II: a severity of disease classification system. Crit Care Med. 1985;13:818-29. Epub 1985/10/01.

121. Cullen DJ, Civetta JM, Briggs BA, Ferrara LC. Therapeutic intervention scoring system: a method for quantitative comparison of patient care. Crit Care Med. 1974;2:57.

122. Keene AR, Cullen DJ. Therapeutic Intervention Scoring System: update 1983. Crit Care Med. 1983;11:1-3. Epub 1983/01/01.

123. Benitz WE, Han MY, Madan A, Ramachandra P. Serial serum C-reactive protein levels in the diagnosis of neonatal infection. Pediatrics. 1998;102:E41. Epub 1998/10/02.

124. Ng PC. Diagnostic markers of infection in neonates. Arch Dis Child Fetal Neonatal Ed. 2004;89:F229-35. Epub 2004/04/23. 
125. Gastmeier P, Geffers C, Schwab F, Fitzner J, Obladen M, RÃ¹/4den H. Development of a surveillance system for nosocomial infections: the component for neonatal intensive care units in Germany. The Journal of hospital infection. 2004;57:126-31.

126. Jiang JH, Chiu NC, Huang FY, Kao HA, Hsu CH, Hung HY, et al. Neonatal sepsis in the neonatal intensive care unit: characteristics of early versus late onset. Journal of Microbiology, Immunology and Infection. 2004;37:301-6.

127. Walter SA, Kjellstrom L, Nyhlin H, Talley NJ, Agreus L. Assessment of normal bowel habits in the general adult population: the Popcol study. Scand J Gastroenterol. 2010;45:556-66. Epub 2010/03/09.

128. Swidsinski A, Dorffel Y, Loening-Baucke V, Theissig F, Ruckert JC, Ismail M, et al. Acute appendicitis is characterised by local invasion with Fusobacterium nucleatum/necrophorum. Gut. 2011;60:34-40. Epub 2009/11/21.

129. Caporaso JG, Kuczynski J, Stombaugh J, Bittinger K, Bushman FD, Costello EK, et al. QIIME allows analysis of high-throughput community sequencing data. Nat Methods. 2010;7:335-6. Epub 2010/04/13.

130. Hooper LV, Gordon JI. Commensal host-bacterial relationships in the gut. Science. 2001;292:1115-8. Epub 2001/05/16.

131. Aspevall O, Osterman B, Dittmer R, Stén L, Lindback E, Forsum U. Performance of four chromogenic urine culture media after one or two days of incubation compared with reference media. J Clin Microbiol. 2002;40:1500.

132. Östholm-Balkhed Å, Tärnberg M, Nilsson M, Johansson AV, Hanberger H, Monstein HJ, et al. Prevalence of extended-spectrum beta-lactamase-producing Enterobacteriaceae and trends in antibiotic consumption in a county of Sweden. Scand J Infect Dis. 2010;42:831-8.

133. Perez-Perez FJ, Hanson ND. Detection of Plasmid-Mediated AmpC \{beta\}-Lactamase Genes in Clinical Isolates by Using Multiplex PCR. J Clin Microbiol. 2002;40:2153.

134. Andersson AF, Lindberg M, Jakobsson H, Backhed F, Nyren P, Engstrand L. Comparative Analysis of Human Gut Microbiota by Barcoded Pyrosequencing. Plos One. 2008;3.

135. Margulies M, Egholm M, Altman WE, Attiya S, Bader JS, Bemben LA, et al. Genome sequencing in microfabricated high-density picolitre reactors. Nature. 2005;437:376-80. Epub 2005/08/02.

136. Edgar RC. Search and clustering orders of magnitude faster than BLAST. Bioinformatics. 2010;26:2460-1. Epub 2010/08/17.

137. Caporaso JG, Bittinger K, Bushman FD, DeSantis TZ, Andersen GL, Knight R. PyNAST: a flexible tool for aligning sequences to a template alignment. Bioinformatics. 2010;26:266-7. Epub 2009/11/17.

138. Neely AN, Maley MP. Survival of enterococci and staphylococci on hospital fabrics and plastic. J Clin Microbiol. 2000;38:724-6. Epub 2000/02/03.

139. Eckstein BC, Adams DA, Eckstein EC, Rao A, Sethi AK, Yadavalli GK, et al. Reduction of Clostridium Difficile and vancomycin-resistant Enterococcus contamination of environmental surfaces after an intervention to improve cleaning methods. BMC Infect Dis. 2007;7:61. Epub 2007/06/23.

140. Hayden MK, Bonten MJ, Blom DW, Lyle EA, van de Vijver DA, Weinstein RA. Reduction in acquisition of vancomycin-resistant enterococcus after enforcement of routine environmental cleaning measures. Clin Infect Dis. 2006;42:1552-60. Epub 2006/05/03.

141. Safdar N, Maki DG. The commonality of risk factors for nosocomial colonization and infection with antimicrobial-resistant Staphylococcus aureus, enterococcus, gram-negative bacilli, Clostridium difficile, and Candida. Ann Intern Med. 2002;136:834-44. Epub 2002/06/05.

142. Clements A, Halton K, Graves N, Pettitt A, Morton A, Looke D, et al. Overcrowding and understaffing in modern health-care systems: key determinants in meticillin-resistant Staphylococcus aureus transmission. Lancet Infect Dis. 2008;8:427-34. Epub 2008/06/28.

143. Scott G. Prevention and control of infections in intensive care. Intensive Care Med. 2000;26 Suppl 1:S22-5. Epub 2000/04/29. 
144. Sullivan A, Edlund C, Nord CE. Effect of antimicrobial agents on the ecological balance of human microflora. Lancet Infect Dis. 2001;1:101-14. Epub 2002/03/02.

145. DiNubile MJ, Friedland I, Chan CY, Motyl MR, Giezek H, Shivaprakash M, et al. Bowel colonization with resistant gram-negative bacilli after antimicrobial therapy of intraabdominal infections: observations from two randomized comparative clinical trials of ertapenem therapy. Eur J Clin Microbiol. 2005;24:443-9.

146. Soussy CJ, Deforges LP, Vanthoi JL, Feghali W, Duval JR. Cefotaxime concentration in the bile and wall of the gallbladder. J Antimicrob Chemother. 1980;6:125-30.

147. Pena C, Pujol M, Ardanuy C, Ricart A, Pallares R, Linares J, et al. Epidemiology and successful control of a large outbreak due to Klebsiella pneumoniae producing extendedspectrum betalactamases. Antimicrob Agents Chemother. 1998;42:53.

148. Ben-Ami R, Schwaber MJ, Navon-Venezia S, Schwartz D, Giladi M, Chmelnitsky I, et al. Influx of Extended-Spectrum Beta-Lactamase-Producing Enterobacteriaceae into the Hospital. Clin Infect Dis. 2006;42:925.

149. Mernelius S, Svensson PO, Rensfeldt G, Davidsson E, Isaksson B, Lofgren S, et al. Compliance with hygiene guidelines: the effect of a multimodal hygiene intervention and validation of direct observations. Am J Infect Control. 2013;41:e45-8. Epub 2013/01/23.

150. Voelz A, Muller A, Gillen J, Le C, Dresbach T, Engelhart S, et al. Outbreaks of Serratia marcescens in neonatal and pediatric intensive care units: Clinical aspects, risk factors and management. International Journal of Hygiene and Environmental Health. 2010;213:79-87.

151. Yoon HJ, Choi JY, Park YS, Kim CO, Kim JM, Yong DE, et al. Outbreaks of Serratia marcescens bacteriuria in a neurosurgical intensive care unit of a tertiary care teaching hospital: a clinical, epidemiologic, and laboratory perspective. Am J Infect Control. 2005;33:595-601. Epub 2005/12/07.

152. Adamson V, Mitt P, Pisarev H, Metsvaht T, Telling K, Naaber P, et al. Prolonged outbreak of Serratia marcescens in Tartu University Hospital: a case-control study. BMC Infect Dis. 2012;12:281. Epub 2012/11/02.

153. Sokol H, Seksik P, Furet JP, Firmesse O, Nion-Larmurier I, Beaugerie L, et al. Low counts of Faecalibacterium prausnitzii in colitis microbiota. Inflamm Bowel Dis. 2009;15:1183-9. Epub 2009/02/25.

154. Chassaing B, Darfeuille-Michaud A. The commensal microbiota and enteropathogens in the pathogenesis of inflammatory bowel diseases. Gastroenterology. 2011;140:1720-28. Epub 2011/05/03.

155. Claesson MJ, O'Toole PW. Evaluating the latest high-throughput molecular techniques for the exploration of microbial gut communities. Gut Microbes. 2010;1:277-8. Epub 2011/02/18. 